رؤية هقترحة لتسطيح النموذج الأساسي وضبطه على البسم

$$
\begin{aligned}
& \text { إعـــــاد } \\
& \text { د. مجلدة هأمورن رسلإنـ سليم } \\
& \text { المدرس بقسم الملابس والنسيج } \\
& \text { كلية الاقتصاد المنزلى - جامعة حلوان }
\end{aligned}
$$

مجلة بحوث التربية النوعية - جامعة المنصورة

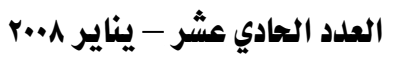




\section{رؤية هقترحة لتسطيح النموذج الأساسي وضبطه على الجسم}

د م مجدةمأموزرسلانسلي

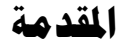

تصميهم النموذج عمليـة فنيـة علميـة بحتـة، وتعـد دراسـة القواعد الأسـاسـية وطـرق البنـاء مـن

الأسساسيات الضرورية اللازم تعليهها.

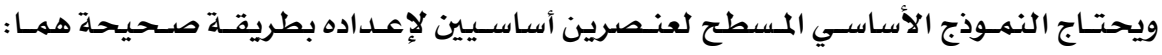

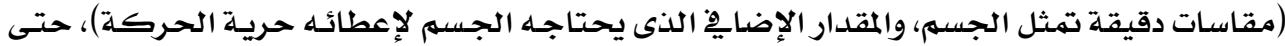

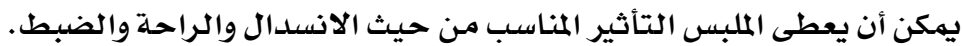

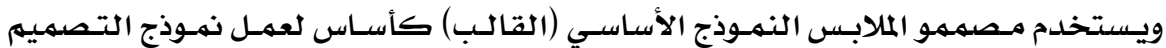

والذى يبـين: خطوط التصميه، الثنيات، علامات التقابل، عدد طبقات القماث التى يتهم القص عليها،

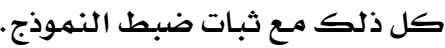

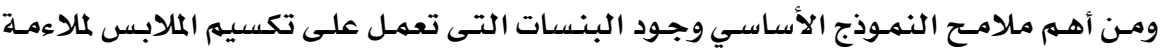

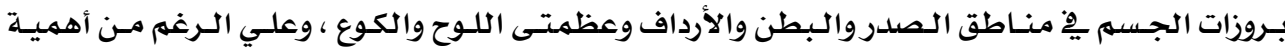

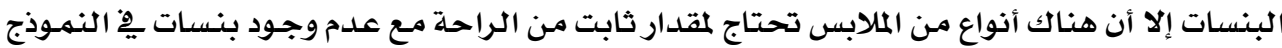

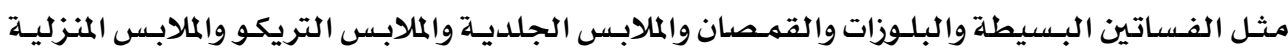

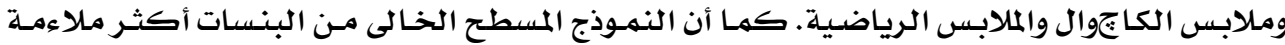
لإنتاج الملابس يِّ مصانع الملابس الجاهزة لسهولة وسرعة التصنيع وبالتالى زيادة الإنتاج.

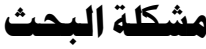

نظراً لتنـوع الملابس التى تحتاج لهـذا النـوع مـن النهـاذج (نهـوذج مسطعح دون بنسـة) فقـد قـام

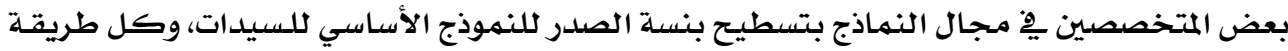
تعطى نتائج معينة من الضبط والراحلة والانسدال.

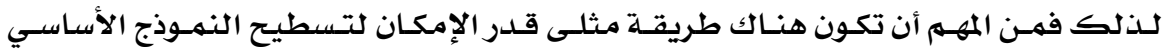

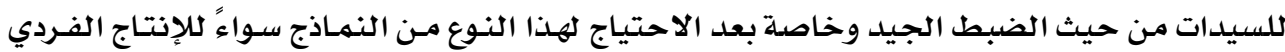
أو الإنتاج الصناعي وذلك لرفع مستوى الجودة لمنافسـة المنتجات العالميلة. وهذا يوضح أهمية وجود طريقة مثلى لتسطيح النموذج الأسـاسي للسيدات سواء يِّ الإنتاج

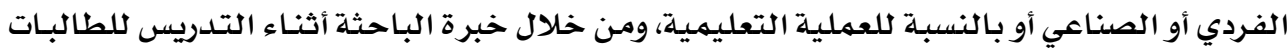

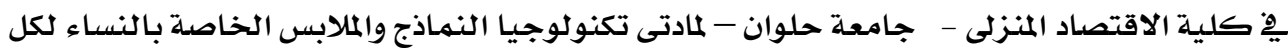
من الفرقة الثانية (فصل دراسى ثانى) والفرقة الثالثة (فصل دراسي أول) ، فقد وجدت الثدات الباحثة صعوبة

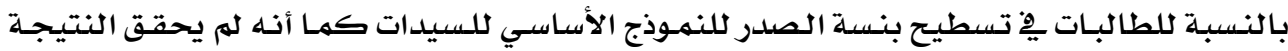


المرجـوة منـه بطـرق التسطيح الأخـرى، مهـا دعـا للـتفكير ِِِ أن يكـون موضـوع البـحـث" رؤيسة مقترحسة

كتسطيح النموذج الأساسي وضبطه على الجسيهم"

تساوقلات البمث:

تتلخحص تساؤلات البحث يْ النقاط التالية:-

- ما هى الفروق بين الطريقة المقترحة لتسطيح النموذج الأساسي والطريقة المعتادة .

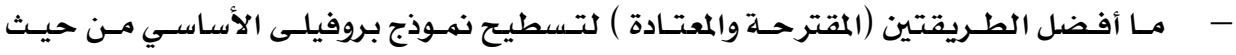

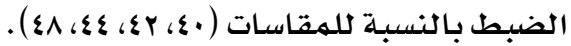

هدف البحث:

يهدف البحث الحالي إلى:

- - محاولة الوصول لطريقة مقترحة لتسطيح النموذج الأساسي للنساء بحيث يتوفر بها أكبر

قدر مـن الضبط والملاءمـة للجسهم ومقارنتها بالطريقة الوفئة المعتادة .

أهمهية البحث:

ترجـع أهمية البحث إلى أنه:-

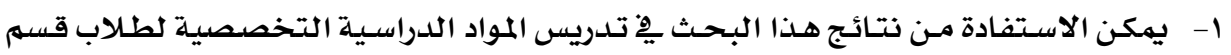

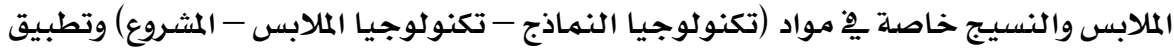

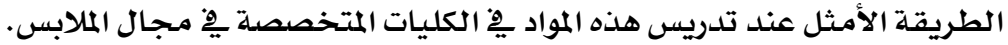

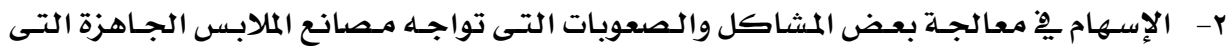

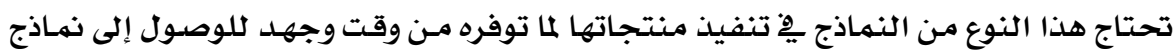

تساعد على الارتقاء بهستوى الجودة.

r- محاولة ريط التعليهم الجامعى بواقع المجتمع واحتياجاته.

ع- توفير دراسة علمية مقننـة لطريقة تسطيح النموذج الأساسي للنساء.

هدود البحث:

تقتصر حدود البحثث على:-

- طريقتين لتسطيح النموذج الأساسي لبروفيلى (Profily) الخاص بالنساء وهما:-

الطريقـة الأولى (أ) وهى: الطريقـة المعتـادة والمتبعـة يِّ التـدريس بالكليـات والمعاهـد والمـدارس

المتخصصة لتسطيح نهوذج بروفيلى (Profily) الأساسي.

الطريقة الثانية (ب) وهى: طريقة مقترحة لتسطيح نموذج بروفيلى (Profily) الأسـاسي. 


$$
\text { تكمن فروض البحث ِِ2: }
$$

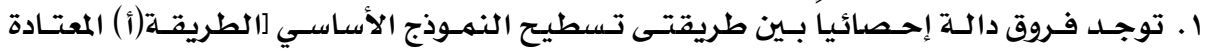

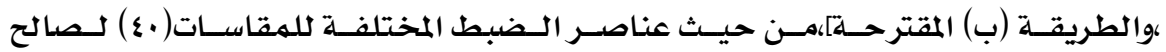

$$
\text { الطريقة (ب). (ب). }
$$

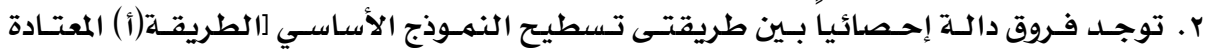

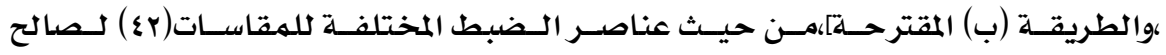

الطريقة (ب). (ب).

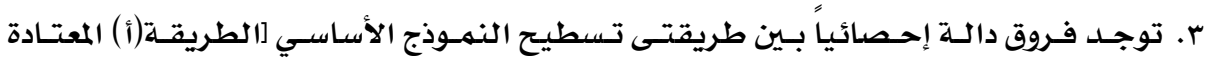

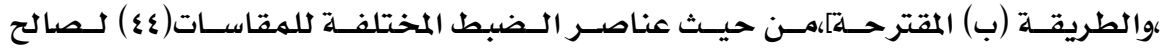

$$
\text { الطريقة (ب). }
$$

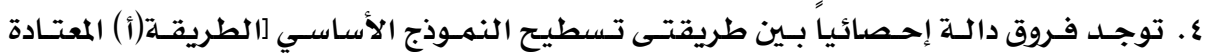

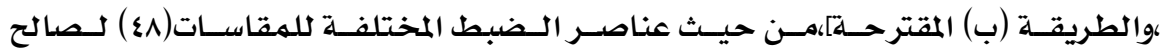
الطريقة (ب). هنهج البمث:

اتبـع البحـث الحسالى المنهج التجريبـى وذلـك لملاءمتـه لتحقيـق أهـداف البحـث والتحقق

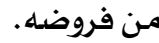

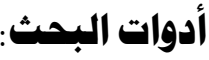
ا ـ نماذج ورقية تمثل النماذج الأساسية والنماذج دون بنسة موضوع الدراسة.

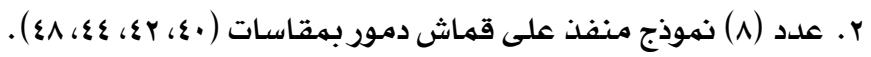

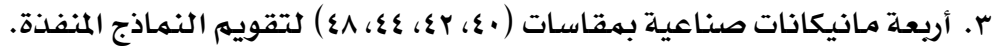
ع. مقياس تقدير النماذج المنفذة.

مر تنفيذ البحث بالإجراءات التالية:تم عمل مسح للدراسات السابقة وقد مر البحث بالإجراءات الآتية:أولاً : : القيام بعمل التجربة التمهيدية.

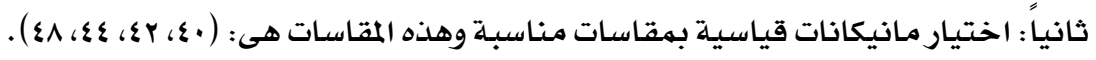
ثالثا: إعداد نماذج ورقية أساسية للنموذج الأساسي المستخدم يِّ البحث. رابعاً: إجراء التجربة الاستطلاعية (تنفيذ النماذج الأساسية بهقاس [ـ عـ وتقييمها ). 


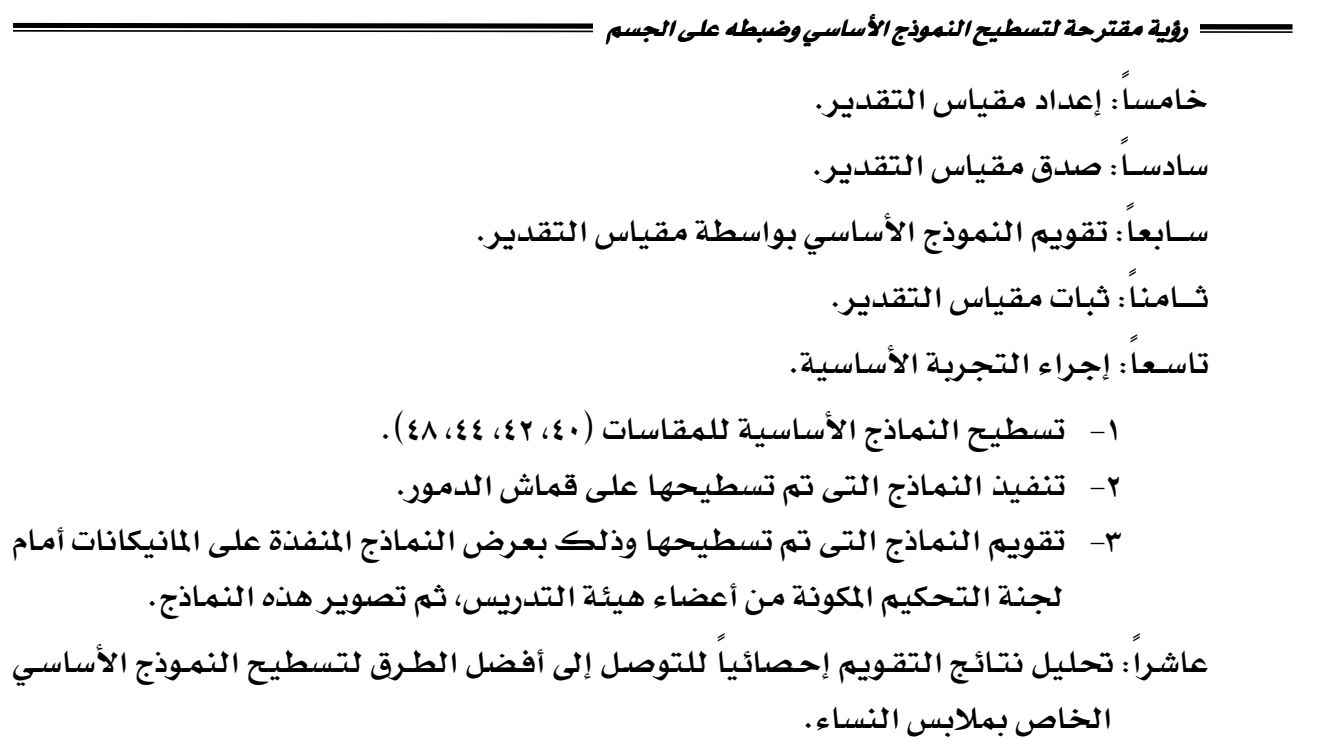

المعاهلات الإحصائية:

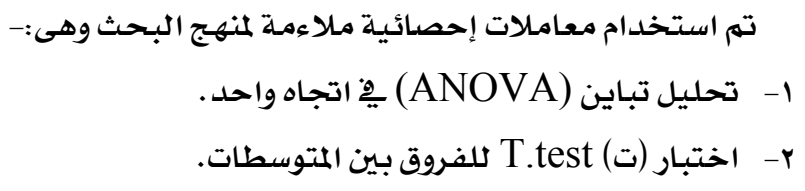

هصطحات البحث:

اـ النموذج (Pattern): مثال الشىء يِّ صورته وجمعه نماذج. (المعجم الوجيز: 1997 : بسا7) - ويقصد بالنموذج هِ اللغة: المثال أو رسم أو تفصيله أو أورنيك. (إلياس أنطون، إدوارد إلياس:

د. د.

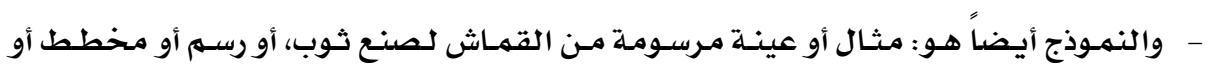

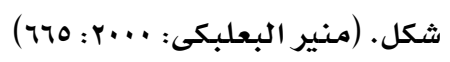

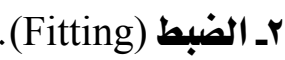

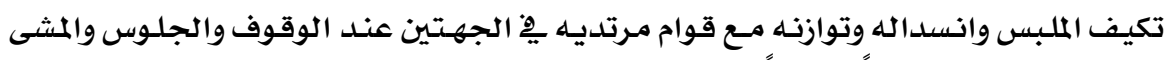

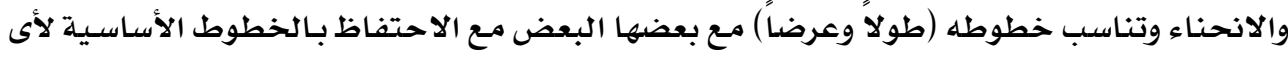

تصميم دون مساس.

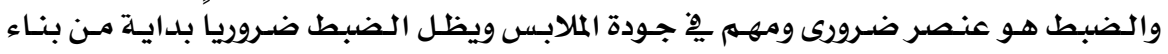

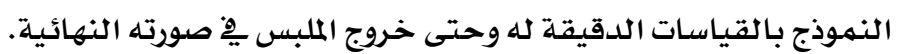

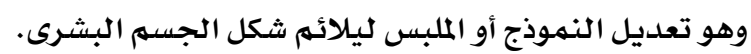

(Thomas, Anna Jacob: 1998: 7) 


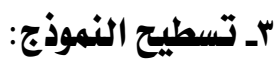

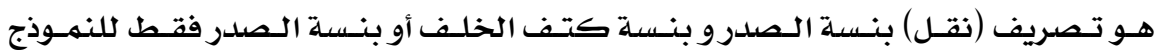

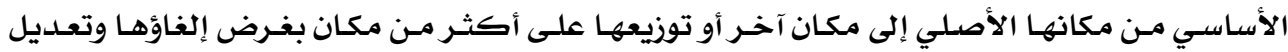

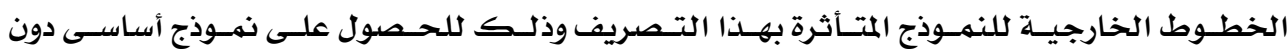
بنسـة صدرر.

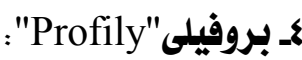

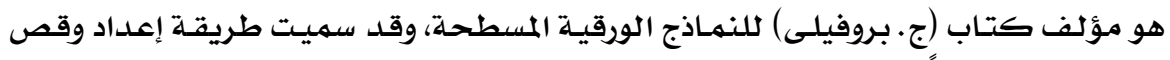

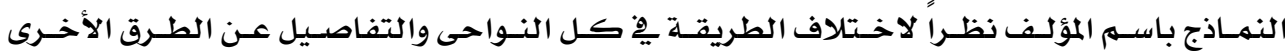

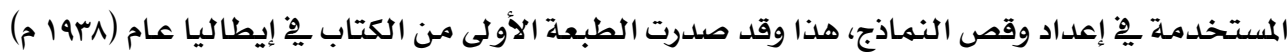

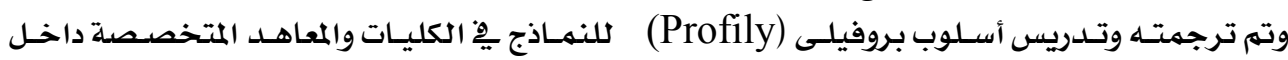

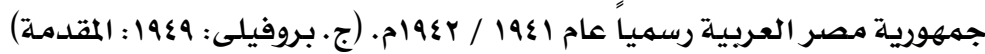

\section{الدراسات والبحوث السابقة التى تناولت بنسات النمهوذج الأساسي:}

\section{اـ دراسة (سنـاء معسروف بخارى) ، 19Ar وعنوانها:}

"الإمكانيات الوظيفية الفنية والزخرفية لبنسات الجزء العلوى من النموذج الأساسي للنساء"

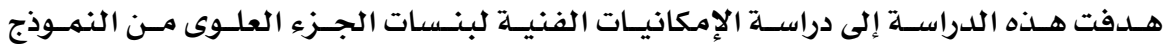

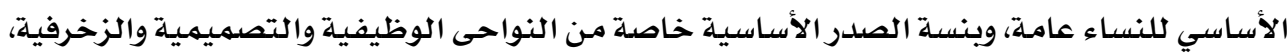

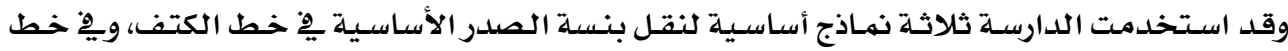

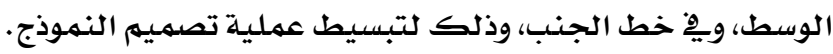
وكانت من أهم النتائج التى تم التوصل إليها هو أن للبنسـة إمكانيات كثيرة فنية ووظيفية

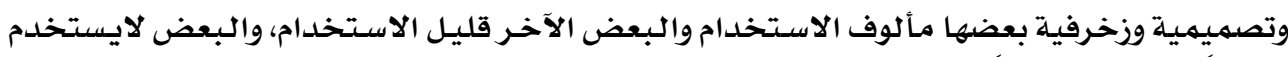
إطلاقا أو يستخدم نادرا لعدم العلهم بـه.

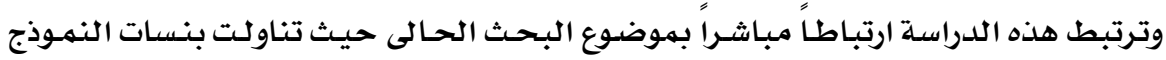

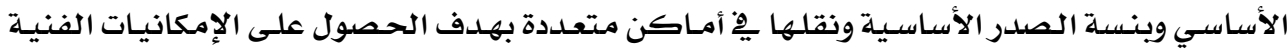

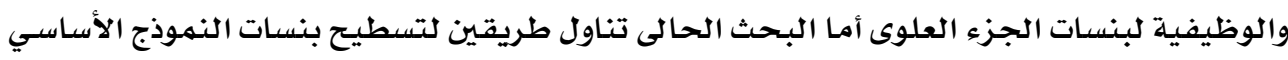

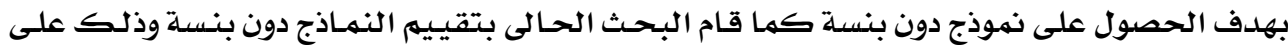

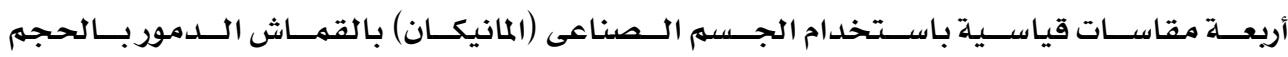




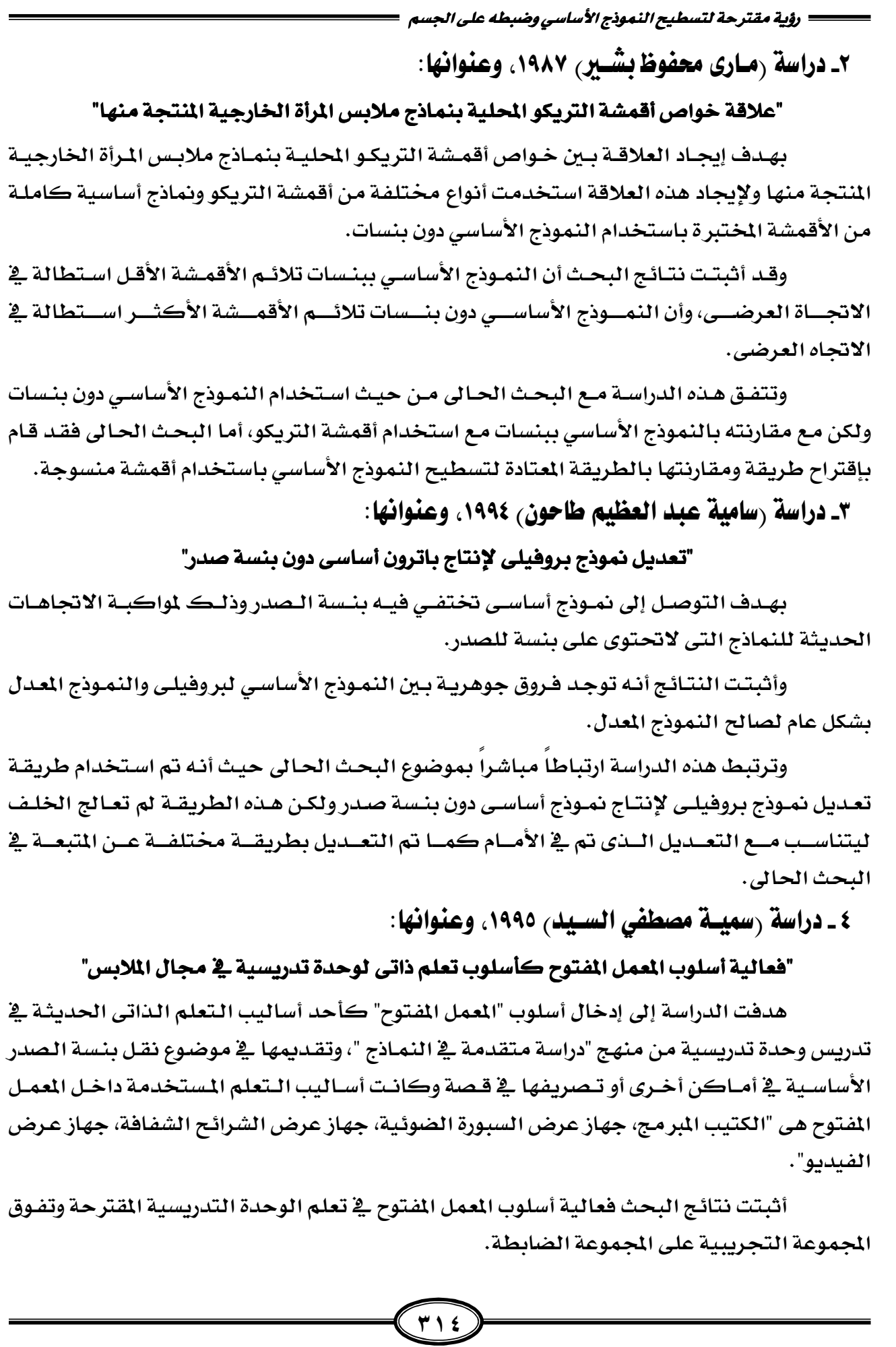




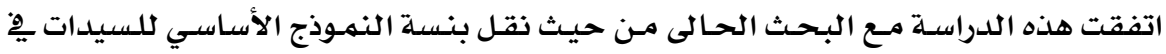

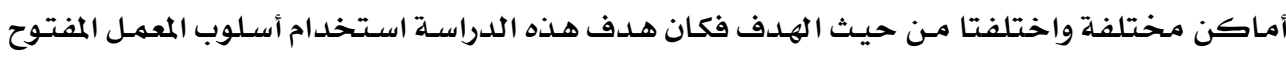

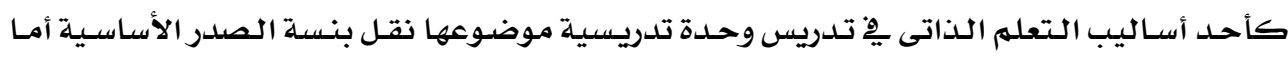

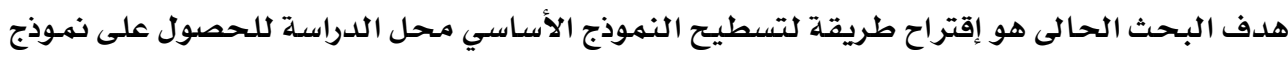
دون بنسـة ومقارنته بالطريقة المعتادة.

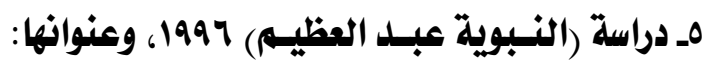

\section{"تأثير نوع النسيج على الإمكانات الفنية الوظيفية والزخرفية لبنسات النموذج الأساسي للجونلة"}

هدفت هذه الدراسـة إلى التعرف على تأثير نوع النسيج على الإمكانات الوظيفيـة والزخرفيـة

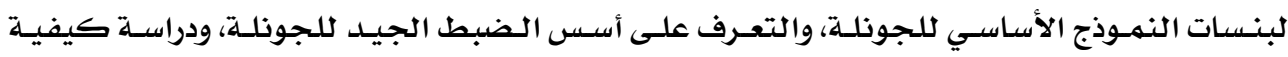

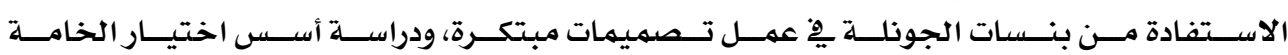

المناسبة للتصميهم.

وأثبتت النتائج أن اختلاف نوع القمـاش يؤثر على الأداء الوظيفي والشكل الجمالى لبنسـة

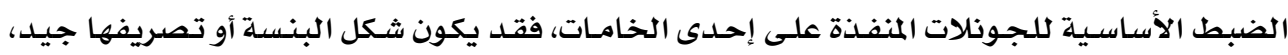
ولكن نفس البنسـة لاتؤدى دورها الوظيفي من ضبط وتشكيل الجونلة على الجسمه.

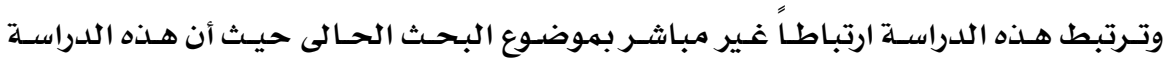

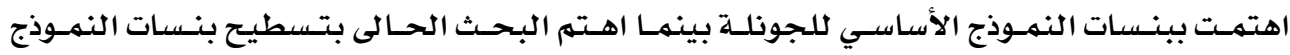

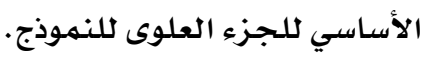

\section{التعليق على الدراسات والبحمث التى تناولت بنسات النيموذج الأساسي:}

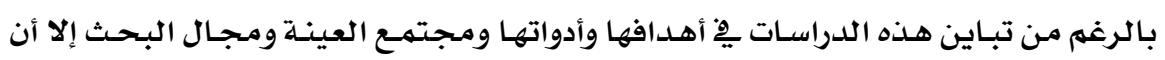

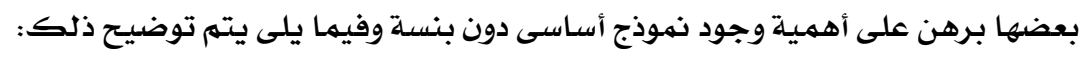

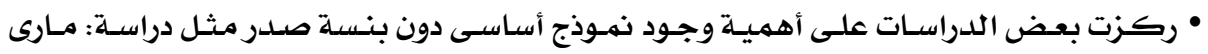

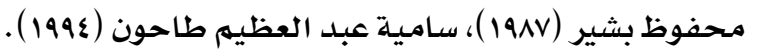

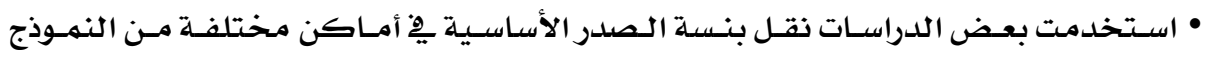

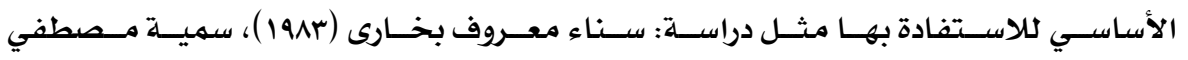
السيد (1990).

• قامت دراسـة سامية عبد العظيه طاحون ( 1999 ) بتعديل نموذج بروفيلى لإنتاج نهوذج أسـاسى دون بنسـة صدر.

• أما دراسـة النبويـة عبد العظيم (1997) فقامت بدراسـة بنسـات النموذج الأسـاسي للجونلة. • معظـم الدراسـات الـسـابقة تم اختيـار موضـوعاتها مــن المنـاهـج والمقـررات الجـامعيـة بهـــف التحديث والتطوير. 


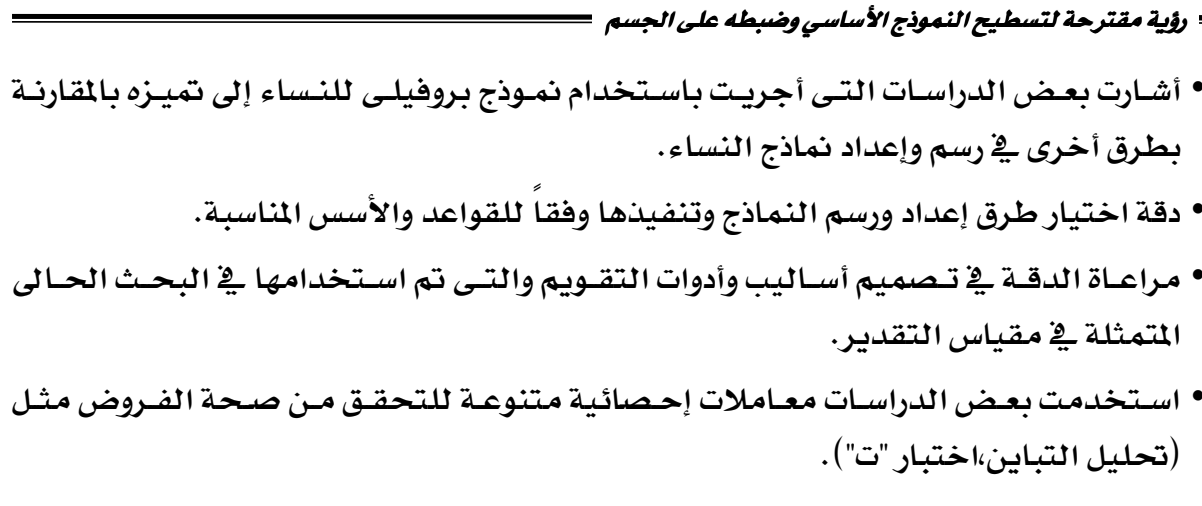

• أثبتـت جميـع الدراسـات أهميـة إعـداد النمـاذج فهي تحتـاج إلى درجـة عاليـة مـن الدقـة والمهارة

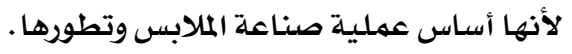

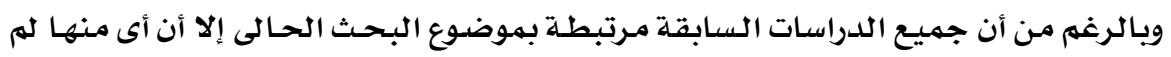

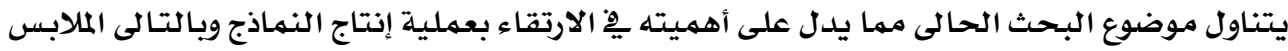
على المستوى الفردى والصناعى. الإطار النظرى للبمث

أولا:مفهوم البنسة (Darts):

البنسـة هى طية مثلثة من القماث تستخدم لجعل القماث المسطح يـتلاءم مـع بـروز الجسهم

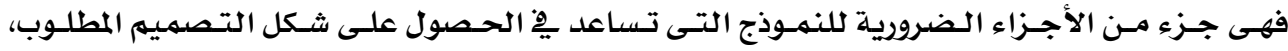

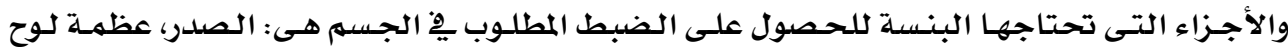
الكتف، البطن، الأرداف. (Nora M. Macdonald: 1997: 281) وهى أيضـاً طيـة مـرتفعـة على التى

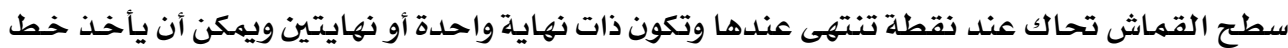

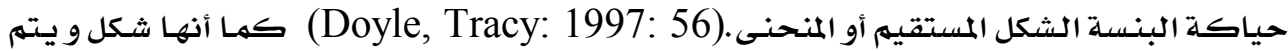

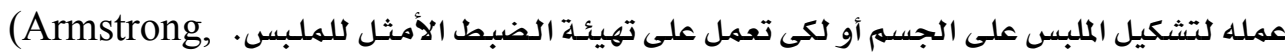
Hellen Joseph: 2000: 13)

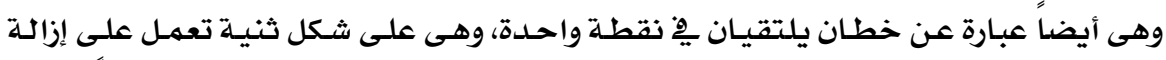

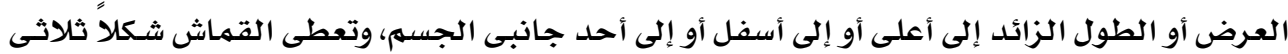
الأبعاد، وهى تحافظ على هذا الشكل فوق منحنيات الجسيم.

كما أنها وسيلة لإزالة الزيادة التى تأخذ شكل مثلث ويؤدى ذلك إلى تكوين أشـكال معينـة على أطراف البنسات، وتتكون بنسات الضبط الأسساسية مـن خلال التقـاء خطوط المسطرة، وقد تكـون

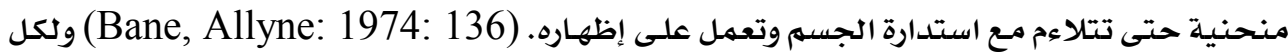

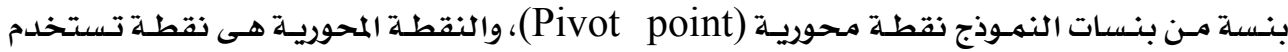

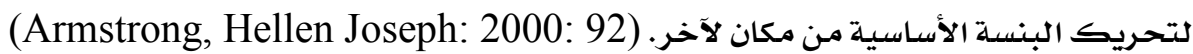




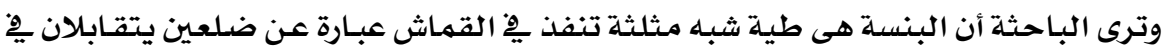

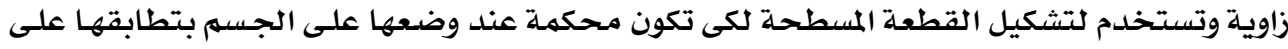

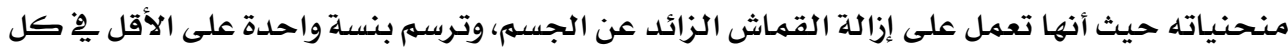

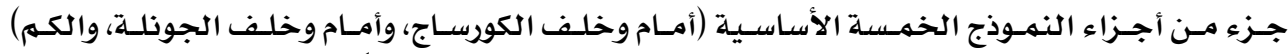

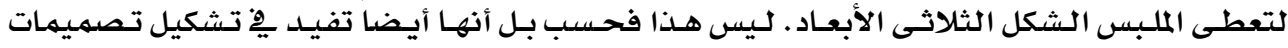
النماذج سواء المسطحة أو التى يتم تشكيلها على المانيكان.

\section{ثانياً: وظيفة البنسة والهدف منهاء النها:}

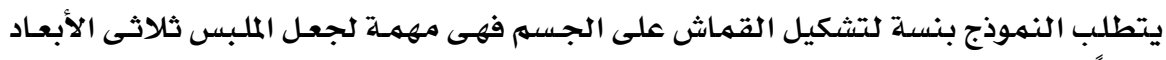

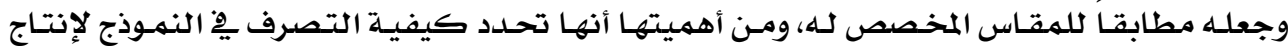

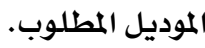

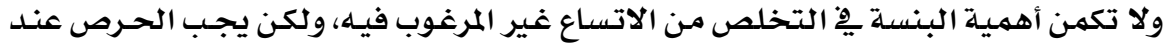

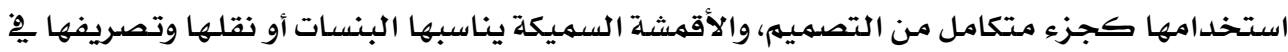

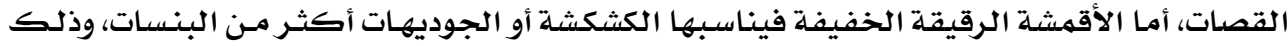

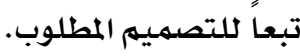

\section{ثاثاً : وصف البنسة ومكوناتها:}

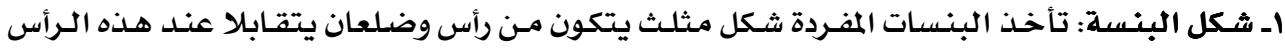

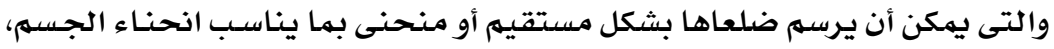
وتستخدم بنسة الصدر كنموذج لتوضيح شكل البنسة فهى تتكون من:

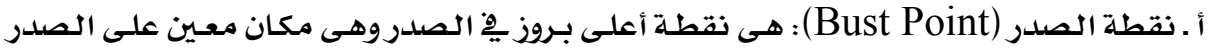

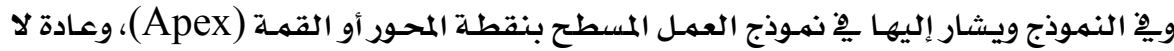

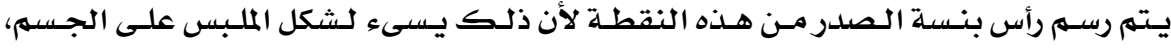

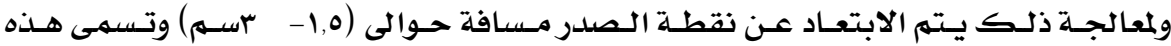

النقطة الجديدة نقطة رأس المثلث أو مركز البنسة أو رأس البنسة (Dart Point)

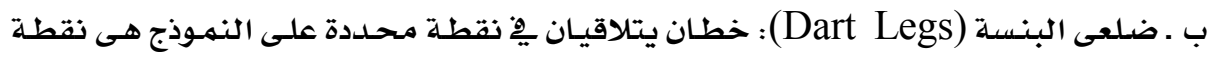

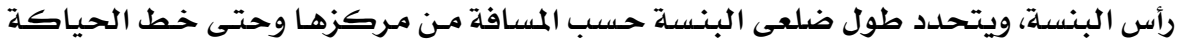

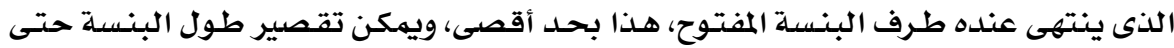

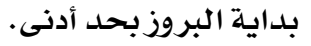

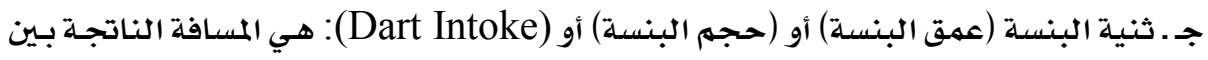

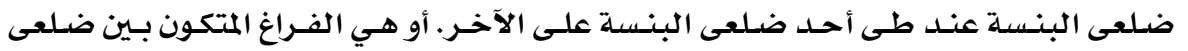

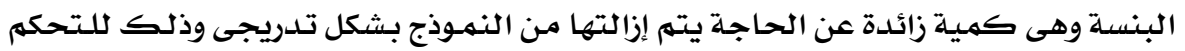


د. ـ قياس زاوية رأس مثلث البنسة (Dart Angle) : يتحسد قياس زاويـة رأس مثلث البنسلة بنـاء

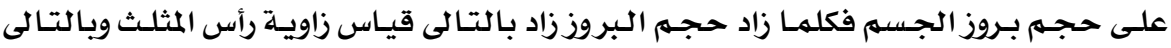
حجـم البنسة والعكس. (Nora M. : 1997:28\& Joseph, Helen:2000:13)

Macdonald

ويوضتح شكل (1) البنسـة ومكوناتها:--

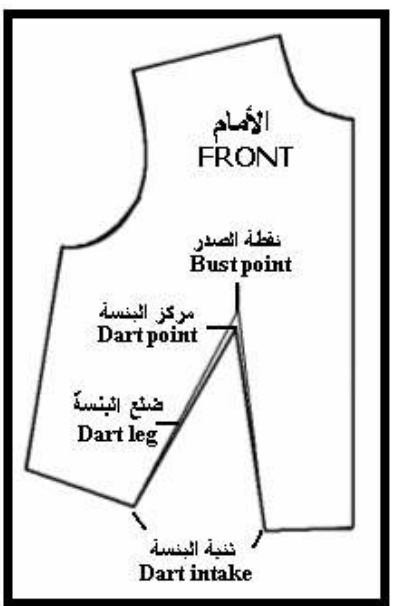

شكل البنسسة ومكوناتها

(Joseph, Helen: 2000: 13)

شكل (1)

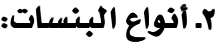

تنقسهم البنسـات إلى عدة أنواع منها:-

أ ـ البنسات الأساسية: Basic Darts

وهى التى يستخدمها مصمهم النهماذج عند رسـم النهـوذج الأسـاسي والناتجـة عنـه مثل بنسـة

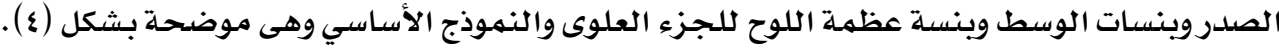

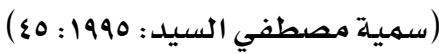

ب ب بنسات الضبط الوظيفية: Fitting Functional Darts

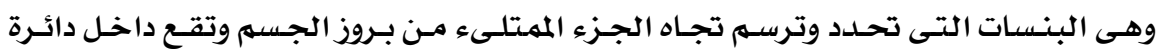

مركز البروز. وتنقسهم البنسـات الوظيفية إلى ثلاثة أنواع هى: 


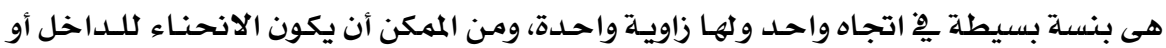

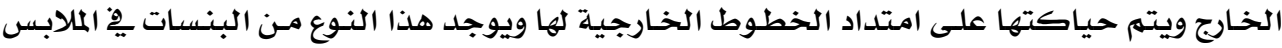

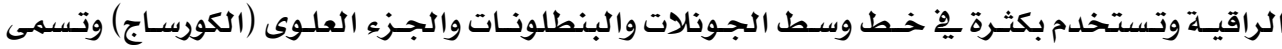

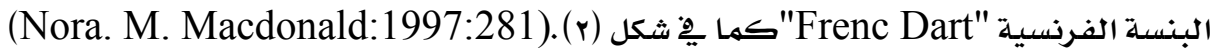
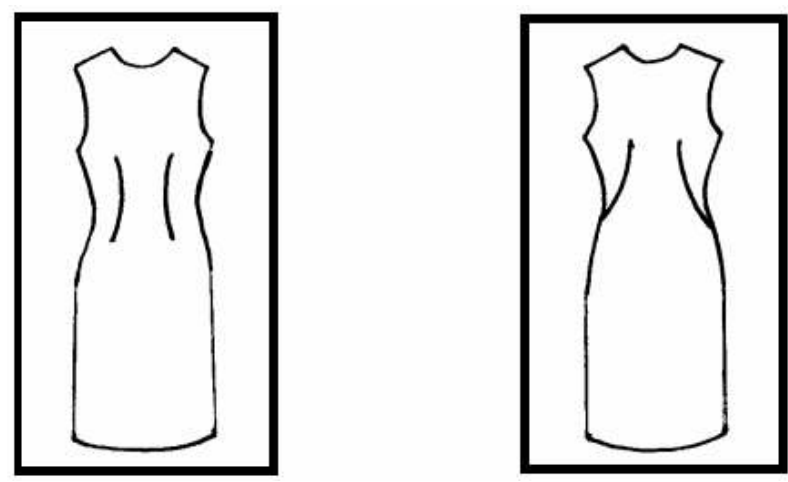

البنسـة الفرنسية ذات الزاوية الواحدة البنسـة المزدوجة

(Batty Brown: 1992: 169) (Batty Brown: 1992: 169)
شكل (r)
شكل (r)

- البنسة ذات الزاويتين (المزدوجة) (Combined Dart)

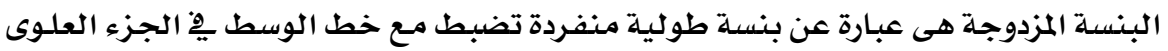

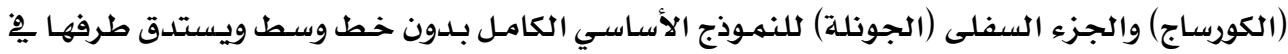

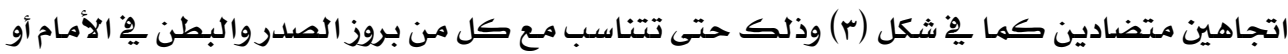

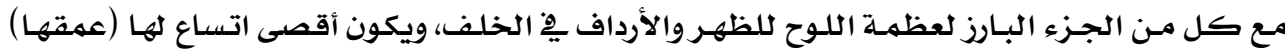
عند خط الوسط وتوجد عادة يِّ الملابس المحبكة المبكة.

(Reader's Digest:1992:159 \& Nora. M. Macdonald:1997:281)

- البنسة غير المنتهية أو البنسة المفتوحة الطرف (Open End Dart):

هى بنسـة مفتوحسة الطرف بمعنى أنها كسـرة أو طيـة وهى بنسـة زخرفيـة أكثر منها بنسـة

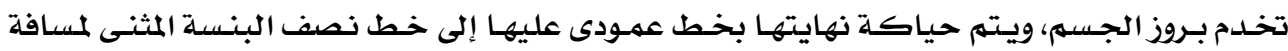

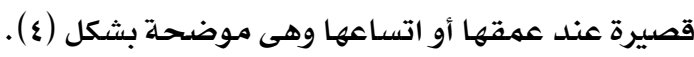

(Norma Hollen: 1965: 33 \& Nora M.Macdonald: 1997: 281) 
جـ.بنسات تصميمية: Style Darts

هى البنسـات التى قد يتمم تقصيرها وتعـديل خطوطها المستقيمة إلى خطوط منحنيـة لكى

تتمشى مـع شكل الجسهم. وإعطاء الشكل النهائى للملبس، وهى التى يتهم حياكتها عند تنفيذ الملابس

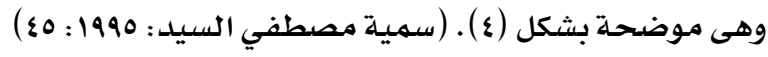

د - البنسات الزخرفية (Decorative Darts):

هـى بنـسـات ترسـهم وتـضـاف إلى النهـوذج بواسـطة القـص والتفتـيح ووظيفتهــا أنهـا تخــدم

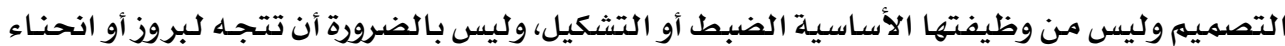

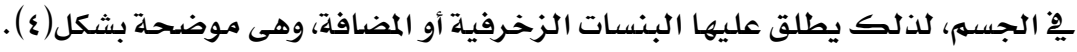

(Norma, Hollen: 1965: 3167 \& Nora M. Macdonald: 1997: 281)

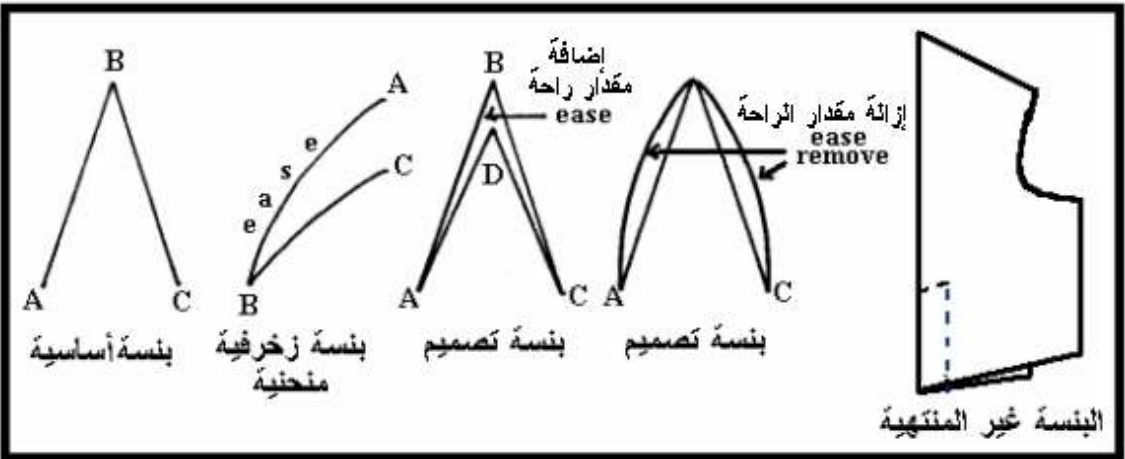

بعض أنواع البنسات (Margolis, Adele.P.: 1971: 37)

شكل (飞)

هـ - أشكال أخرى من البنسات:

- البنسات غير المتوازية (Non parallel Darts) -

وهى مججموعة بنسات تأخذ شكل المروحة، كما بشكل (ه).

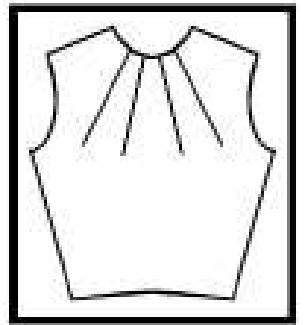

البنسات غير المتوازية (Nora M.Macdonald: 1997: 47)

(0) شكل (0) 
- البنسات المتوازية (Parallel Darts): وهى التى تتكـون مـن بنستين تقعـان على خطوط البنسة بحيـث تكونـا متوازيتـان، وهى

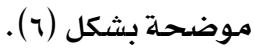
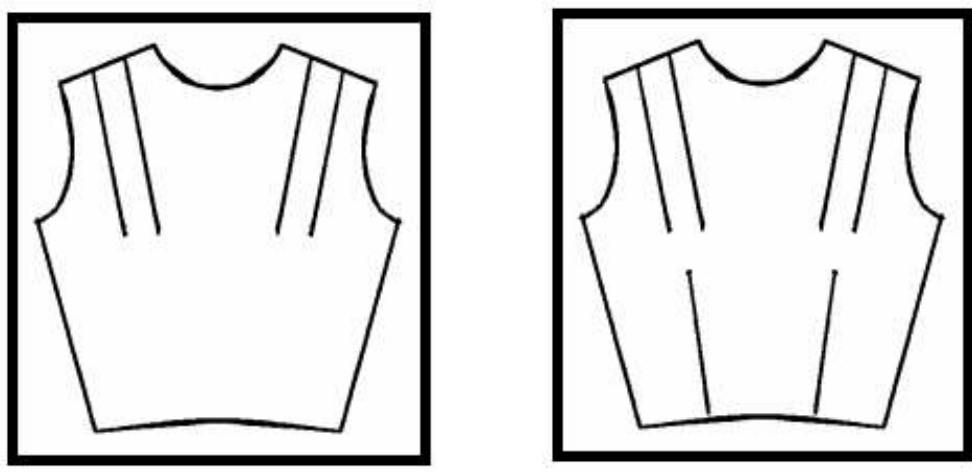

البنسات المتوازيـة البنسـة الواحدة المقسمة

(Nora M.Macdonald: 1997: 46) (Nora M.Macdonald: 1997: 44)

(v) شكل

شكل (؟)

- البنسة العائمة (Released Dart):

وهى بنسة لاتحاك كلية مسببة اتساع أو مظهر ممتلىء للجسه.

- البنسة الواحدة المقسمة (Single - Divided Darts):

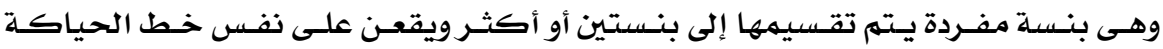

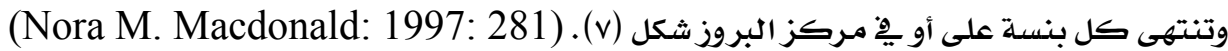

د- اتجاه طى مسافة البنسة (زيادة البنسة):

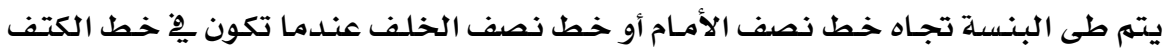

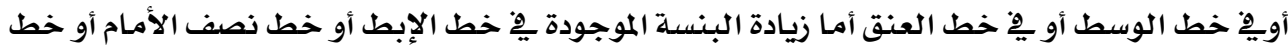

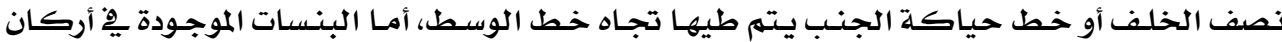

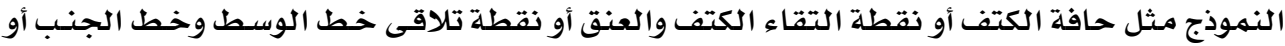

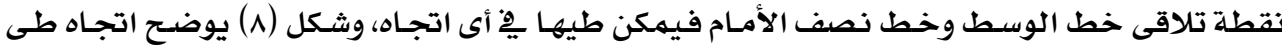

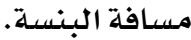




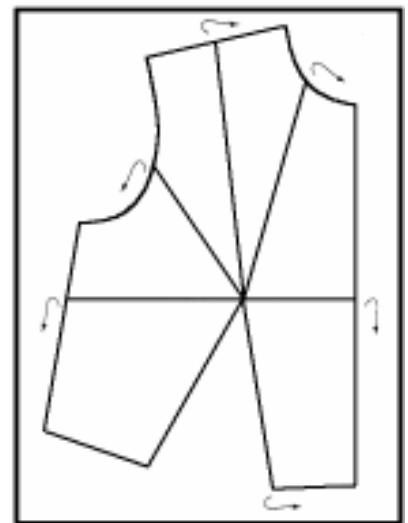

اتجاه طى مسافة البنسة

(Armstrong, Helen Josef: 2000: 13)

شكل (^)

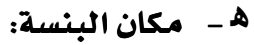

يتميـز النمـوذج الأساسـي المسطح بأنه ينفـذ مـن خـلال بعـدين (طول - عـرض) فقط بينما

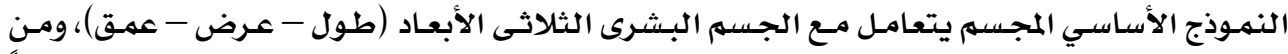

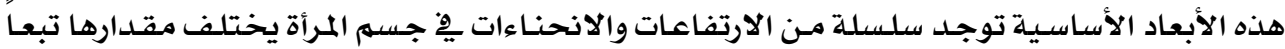

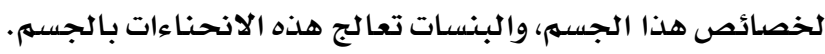

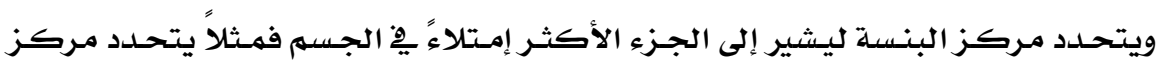
بنسة الصدر ليشير إلى نقطة أعلى بروز الصدر (Apex). M. Macdonald: 1997: 12).

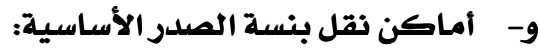

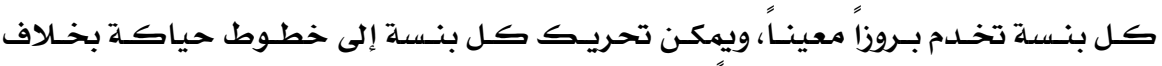

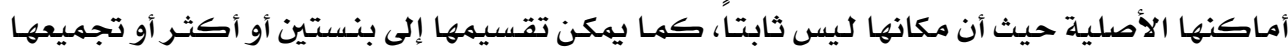

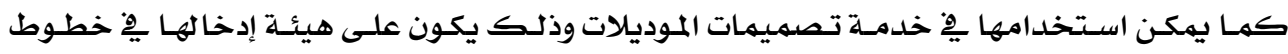

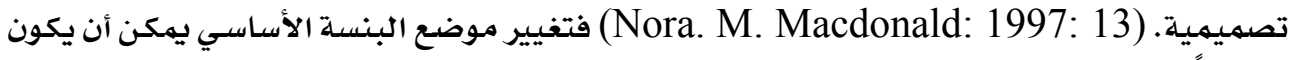

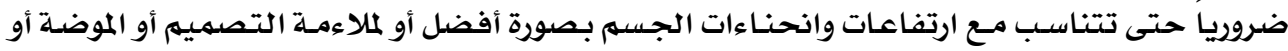

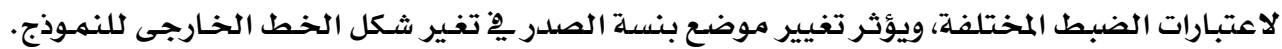

(Bray, Natalie: 1987: 29)

فيمكن نقل بنسـة الـصدر إلى أى موقـع على حـدود النمـوذج الخـارجيـة مـن النقطـة المحوريـة

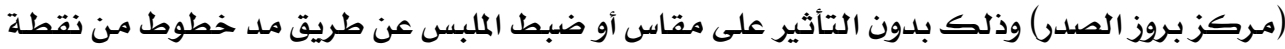

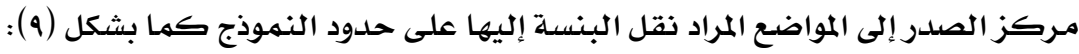




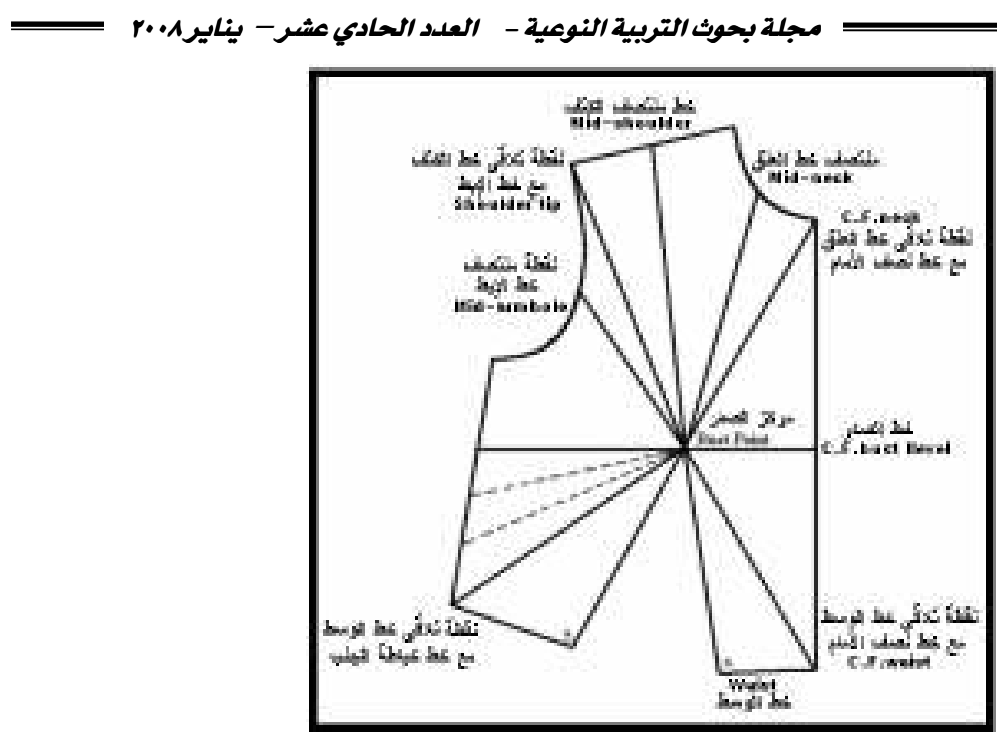

أماكن نقل بنسة الصدر على حدود النموذج

(Armstrong, Helen Josef: 2000: 69)

شكل (a)

ز- تقنيات نقل بنسة الصدر:

ولنقل بنسة الصدر تقنيات مختلفة منها:-

Single dart series - slash تقنيـة شق مكان البنسة الجديد ونقل البنسة الأساسية إليها: :spread technique

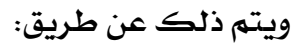

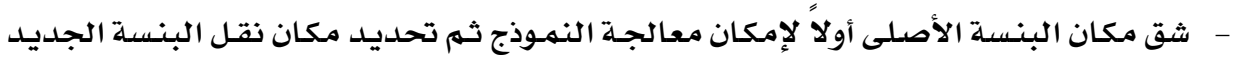

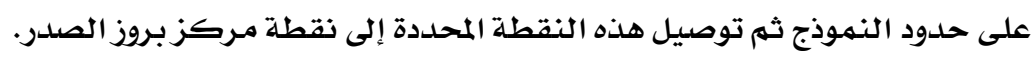

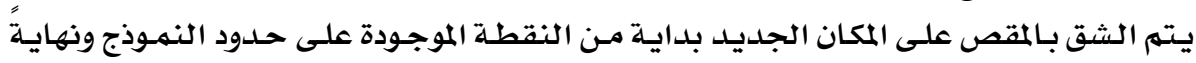

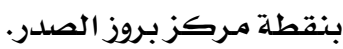

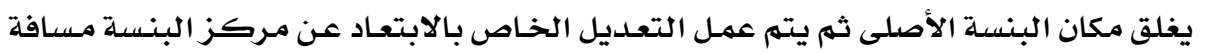

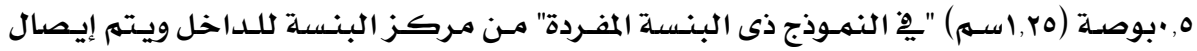

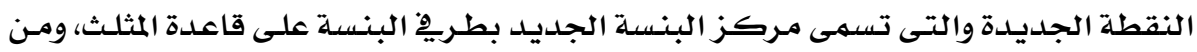

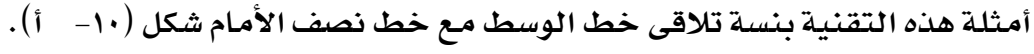
ملحوظة: مكان بنسة الصدر الأساسية هنا مع بنسة وسط الأمام. 


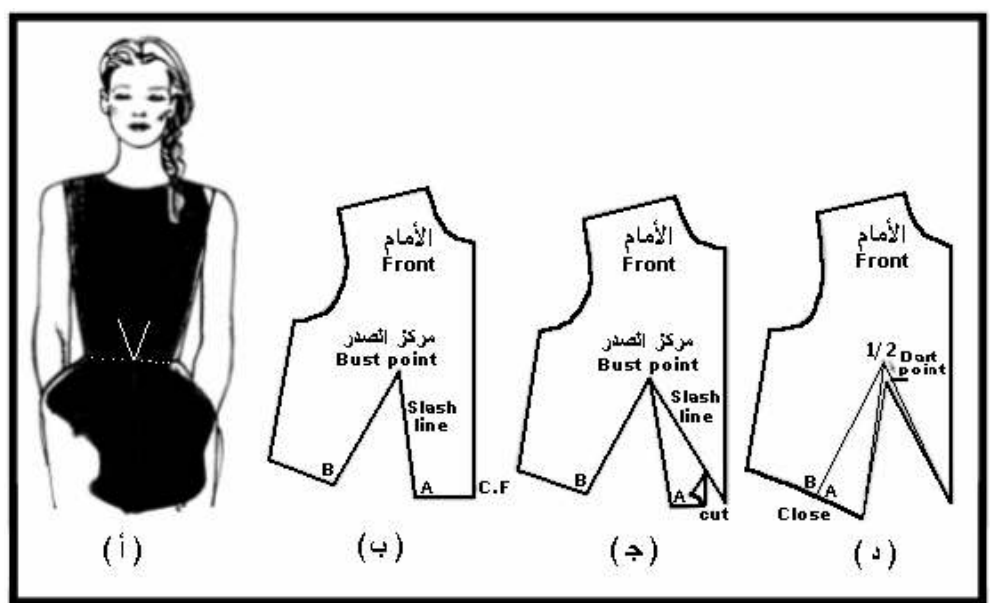

تصميهم تم نقل بنسـة الصدر بـه ِِّ نقطة تلاقى خط الوسط مـ خط نصف الأمـام (Armstrong, Hellen Joseph: 2000: 70 - 71)

$$
\text { شكل (1.) }
$$

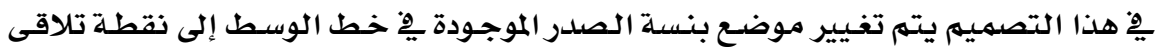

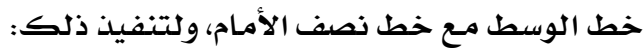

$$
\text { يتمى شف حدود النموذج الخارجية مـع شف موضـع البنسـة الأصلى. }
$$

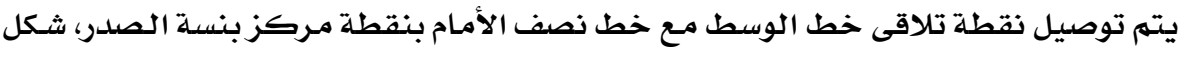

$$
\text { (-1.) }
$$

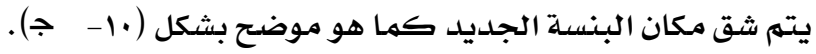

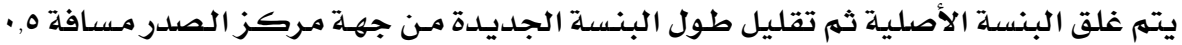

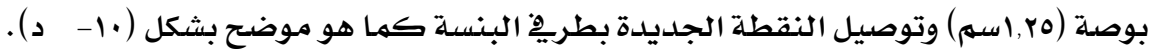
وبذلك يكون قد تم نقل بنسة الصدر إلى المكان الجديد (نقطة تلاقى خط نصف الأمـام مـع خط الوسط).

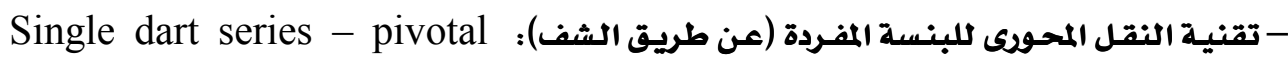
:transfer technique

$$
\text { ويتهم ذلك عن طريق:- }
$$

- شف الحدود الخارجية للنموذج الأساسي مـع شف البنسـة الأصلية ثم تحديلد مكان نقل البنسـة

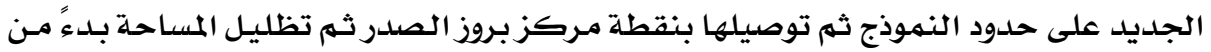

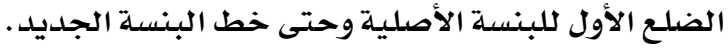


- شـف هـذا الجـزء المظلـل ثم تحـريــك ورق الشف لاسـتكمال شـف بـاقى النهـوذج (الجـزء الغـير

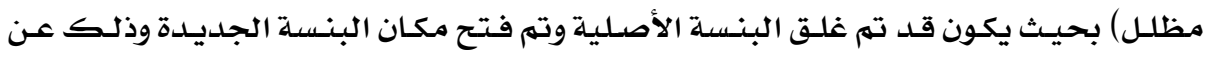
طريق الشف المحورى. - الابتعاد عن مركز بروز الصدر ثم توصيل النقطة الجديدة بطريِّ البنسة الجديدة. ومن الأمثلة على هذه التقنية:

بنسـة منتصف خط الرقبـة شـكل (11- أ) وتنفيـذها بـالخطوات السـابقة كمـا بالأثـكال (11- ب)، . (-11)، (-11)

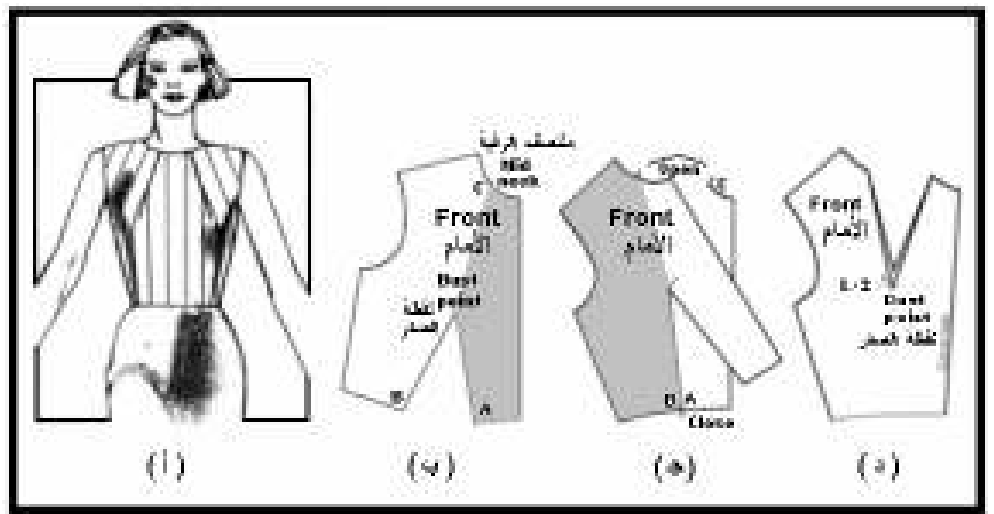

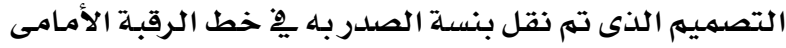

(Armstrong, Hellen Joseph: 2000: 75)

شكل (11)

\section{خطوات إجراء التجارب العملية:}

أولاً:التجربة التههيدية:

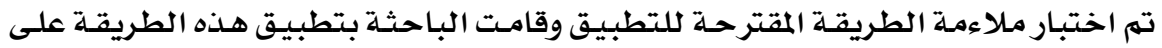
طالبـات الفـرقتين الثانيـة والثالثـة جامعـة حلـوان والفرقـة الثالثـة جامعـة الأزهـر للعـامـين الجـامعيـين

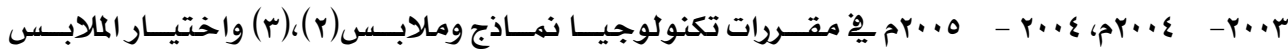
وتتفيـذها حيـث أن الطالبـات تحتـاج ِِِ هـذا المقـرر لتسطيح نهـوذج بروفيلى لعمـل بعض التصميمات

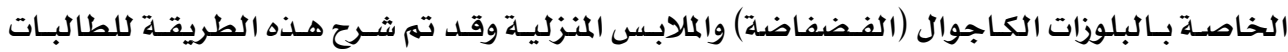

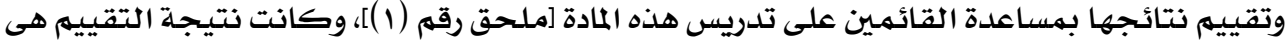

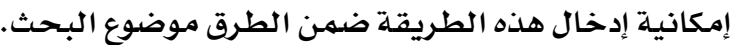




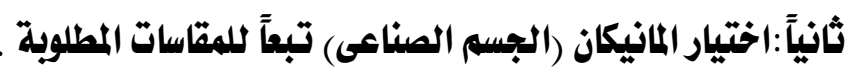

وقد تم استخدام مانيكانات قياسية للتحكيهم عليها ولهم تستخدم الباحثة القياسـات المقنــة

$$
\text { بالجداول الخاصدة للأسباب الآتية:- }
$$

1 - عدم وجود مواصفة قياسية لمقاسات السيدات ِِّ مصر.

ץ - تختلف قياسات الجداول كل عن الآخر ولذلك وجب توحيد القياسات لإمكان المقارنة، فتم

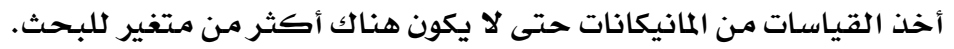
كما أنه له يتم استخدام أشخاص فعليين لتحكيم النماذج عليهم للأسباب الآتية:أ - صعوبـة وجود أشخاص ذوى قياسات متتناسبـة الأطوال والمحيطات.

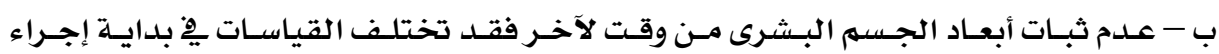
التجرية عن وقت التحكيهم.

جـ - إمكانية وجود عيوب جسمية يكون لها تأثير مباشر على كفاءة التحكيه.

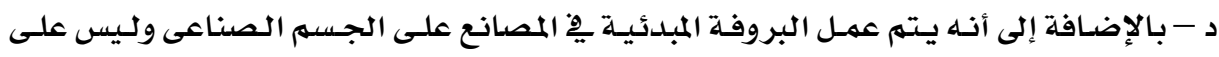

$$
\text { الجسم البشرى. }
$$

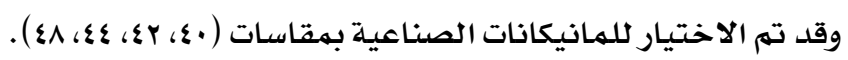

وتهم أخـذ قيـاسـات المانيكانات الصناعية لكل مقاس من القياسات الخاصدة بالمانيكانات الأريع

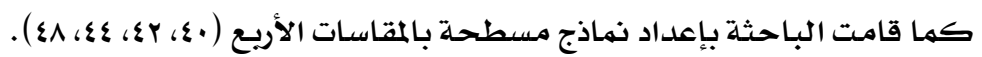

ثالثاً: التجربة الاستطاعية.

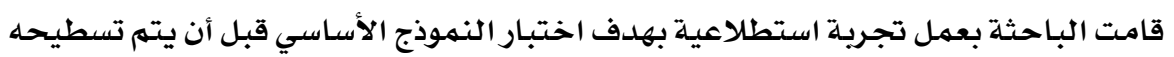
وذلك لمعرفة أن ظهور أى عيوب يرجع إلى النهموذج الأسـاسي.

رابعاً: إعلداد مقياس التقدير.

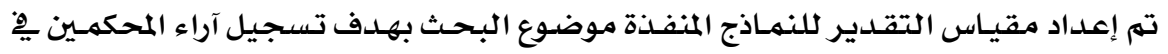

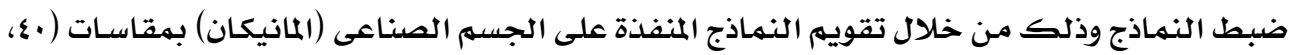

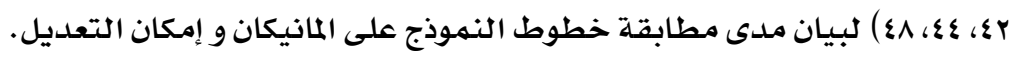

$$
\text { - الجوانب الأساسية لمقياس التقدير:- }
$$




\section{خامساً: صلدق مقياس الققدير.}

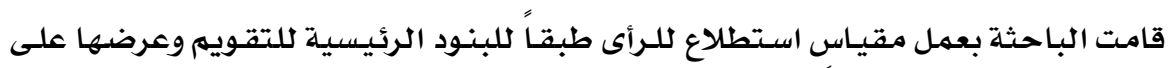

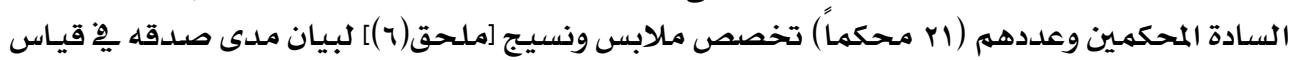

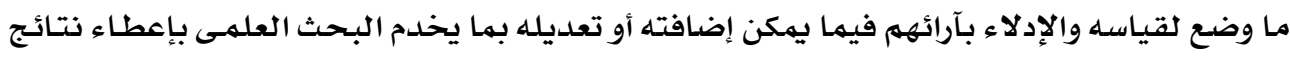

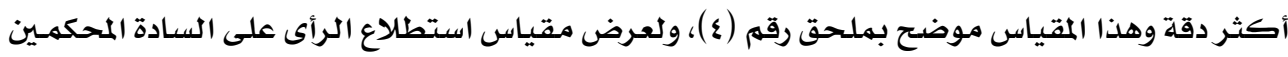

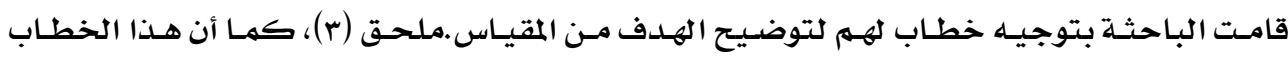

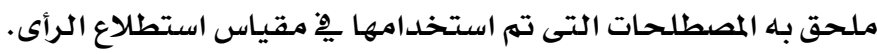

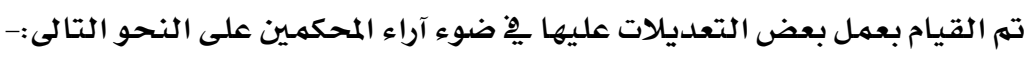

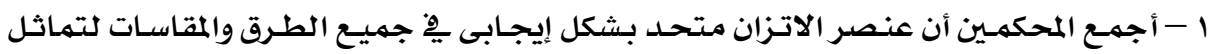

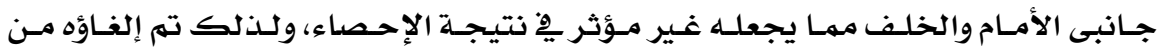
مقياس التقدير.

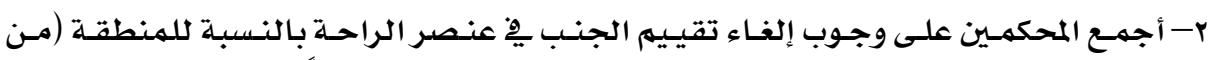

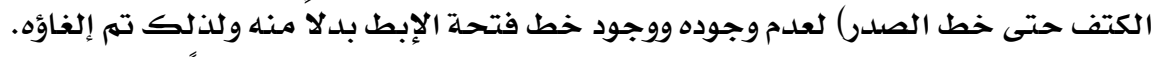

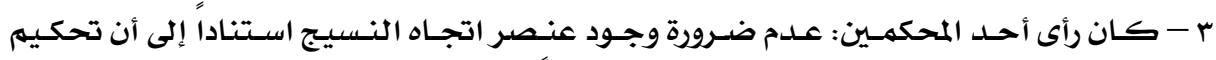

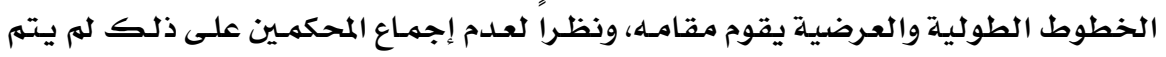
إلغاؤه كما أنه عنصر مهـم فِّ التحكيم لايمكن إغفاله.

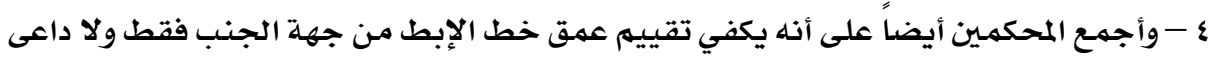

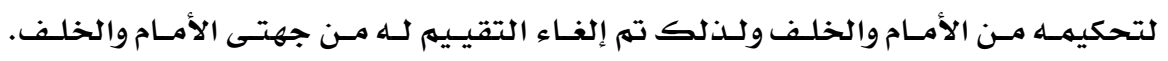

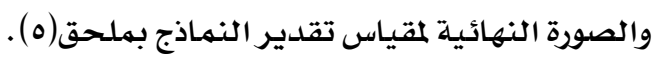

\section{سادسا: تقويم النماذج الأساسية المنفذة بواسطة مقياس التقدير النقانير}

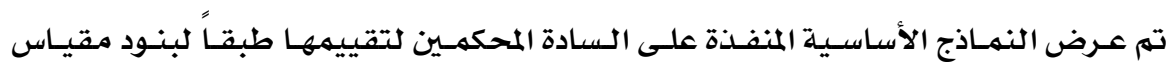

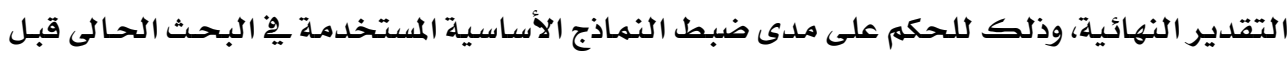

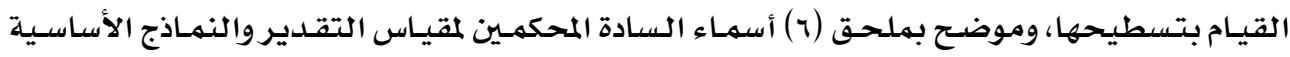

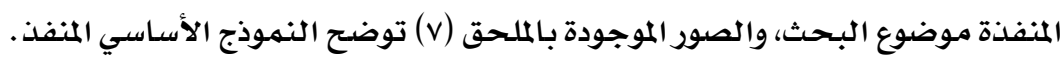
سابعاً: ثبات مقياس التقدير.

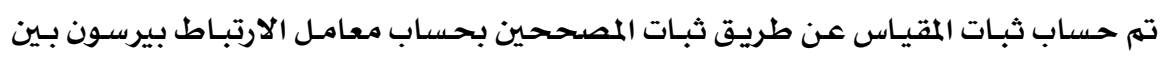

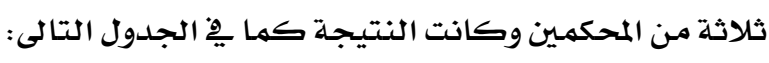


جدول رقم (1) - (1)

معاملات الارتباط بين ثلاثة من المحكمـين لطرق التسطيح الخمسـة

\begin{tabular}{|c|c|c|c|c|c|}
\hline$(\Delta)$ & ر) & (ج) & ر(ب) & (i) & المحكمين \\
\hline$* \cdot, 91$ & $\bullet \cdot\{\Lambda$ & $\diamond \cdot, \varepsilon V$ & * *,ar & $\bullet \cdot, \AA$ & $r-1$ \\
\hline$\leftrightarrow, \varepsilon V$ & $\bullet \cdot, \Sigma V$ & $\bullet \cdot \cdot, 91$ & * *,ar & $* \bullet \cdot, 91$ & $r \quad-1$ \\
\hline$* * \cdot, 9 r$ & $* *, 91$ & $* *, 91$ & $\leftrightarrow, \varepsilon V$ & $* \cdot, 4 r$ & $r \quad-r$ \\
\hline
\end{tabular}

ارتباط ( ه ) معنوى عند مستوى معنوية ه.,.

ارتباط ( * * ) معنوى عند مستوى معنوية ا +, •

يتضح من الجدول السـابق أن قيم معامـلات الارتبـاط بين المحكمـين موجبـة ودالة عند مستوى

0, • ا •, • وهذا دليل على أن المقياس ثابت ويعطى نفس الدرجات عند تكراره.

ثامنا: إجراءات التجربة الأساسية.

الهـدف مـن التجريـة: التوصـل إلى أفضل طريقـة لتسطيح النهـاذج الأسـاسية للسيدات مـن

حيث الضبط والملاءمـة للجسم.

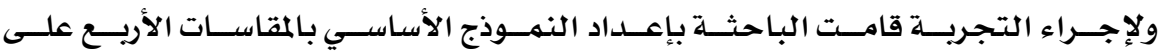

النحو التالى:-

- نسختان من كل مقاس للنموذج الأسـاسي لبروفيلى (Profily).

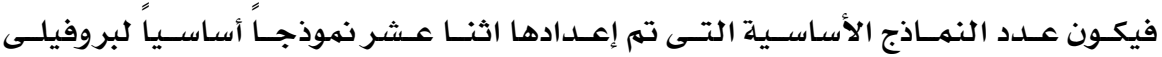

(Profily)

: 1 تسطيح النماذج

قامـت البـاحثـة بتـسطيح النهـاذج الأسـاسـية الخـاصسة بكل طريقـة تبعـاً لطريقـة التسطيح

الخاصة بها.

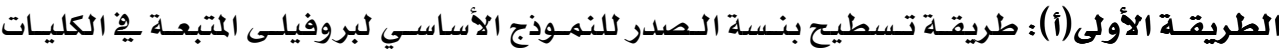
والمعاهد والمدارس المتخخصصئ.

• بالنسبـة لكلأمام:

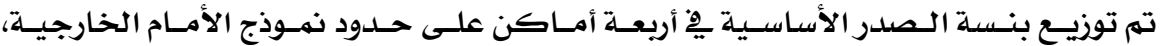

- ـ/ عسم مِ منتصف خط العنق الأمـامى.

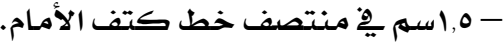

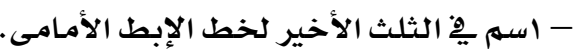

- باقى مقدار بنسـة الصدر الأمامية يتهم تصريفه يِْ بنسة وسط الأمام. 


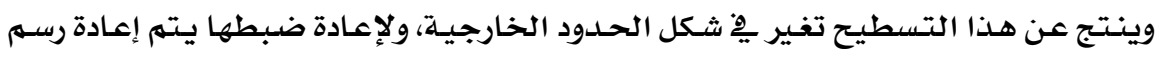

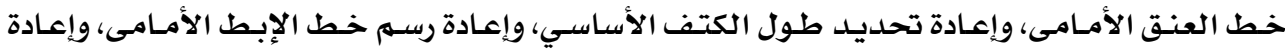
تحديد عرض نهاية نموذج الأمام من أسفل ليعود إلى مقاسه الطبيعى الطئ. • بانتسبسة كلخلف:

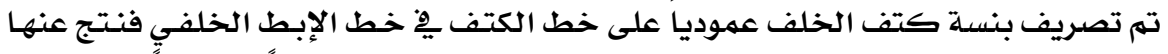

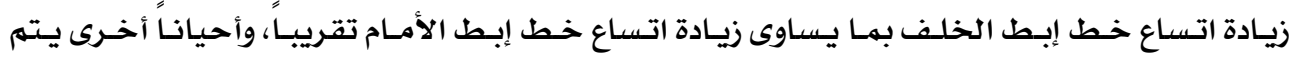

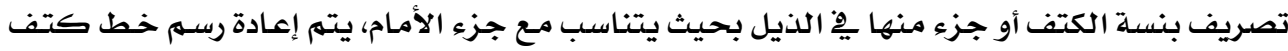

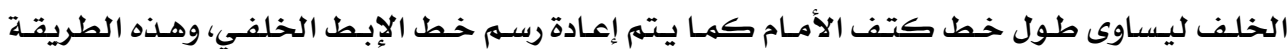
بشكل (19).

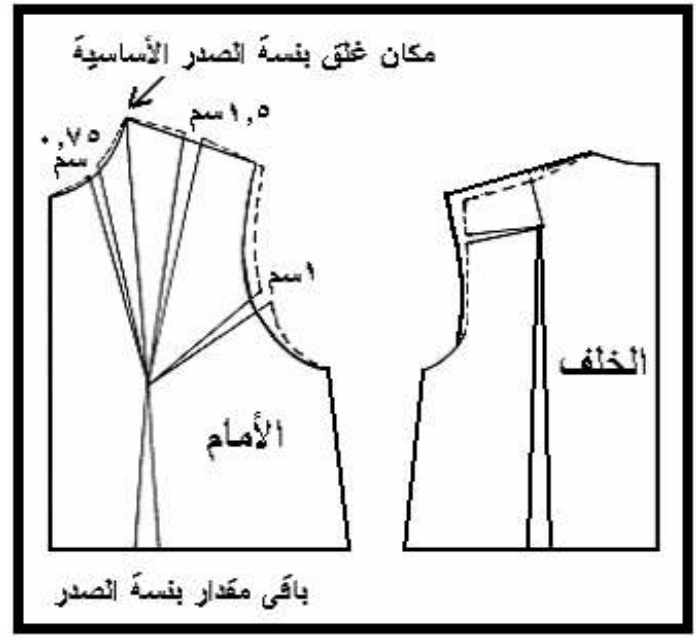

طريقة تسطيح بروفيلى التى يتم تدريسها يِّ الكليات والمعاهد والمدارس المتخصصدة

شكل (17)

الطريقة الثانية(i) : الطريقة المقترحة يُ البحث الحالى.

تم تسطيح النموذج كالآتى:-

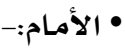

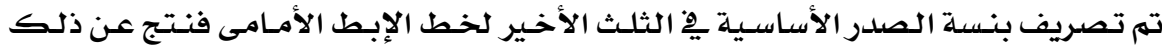

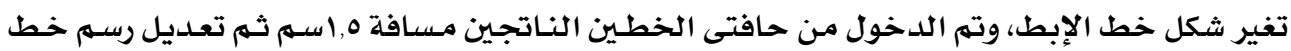

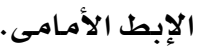


تم تصريف بنسـة كتف الخلـف يْ خـط الإبط الخلفي بشكل عمـودى على خط منتصف البنسـة عند مـركزها فنتج عن ذلك أبضا تغير شكل خط الإبـط، ولضبطه تم الدخول على حافتى الخطين الناتجين من التصريف مسـافة V مهر.

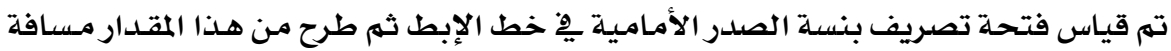
مقدار فتحة تصريف بنسة كتف الخلف. تم إضافة المقدار الناتج إلى كل من بداية ونهاية خط كتف الخلف لأعلي ، أمـا نقطـة عمق

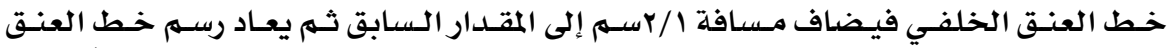
الخلفـي وخـط كتـف الخلـف مـع مـراعـاة أن يكـون طـول خط كتف الخلـف مسساويا لخـط كتف الأمام.

تم رسم خط الإبط الخلفي من جديد ليأخذ نفس الشكل الأول. كما بشكل (IV).

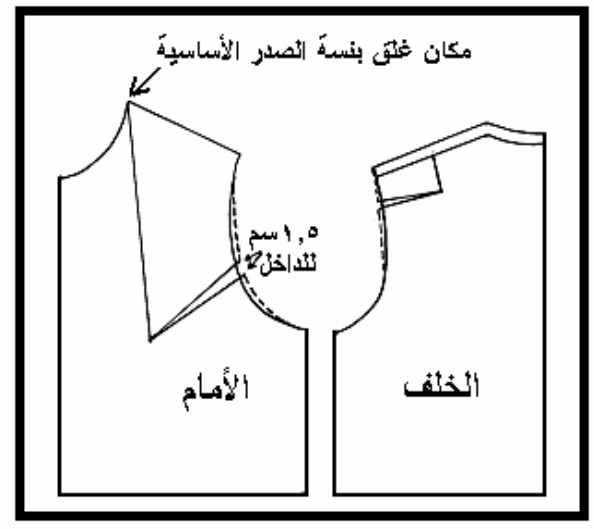

$$
\text { الطريقة المقترحة لتسطيح نهوذج بروفيلى }
$$

شكل (IV)

وترى الباحثة أن طريقة التسطيح المقترحة تتميز بما يلى:-

- عمق خطى إبط الأمام والخلف مناسباً للاستخدام حيت يكونا أكثر عمقاً على عكس ذلك الك

$$
\text { مِ النموذج الأساسي. }
$$

- ميـل خطى كتـف الأمـام وكتف الخلـف أكثر ضـبطـا مـن النهـوذج الأسـاسـي حيـث يقـل ميليهما.

- طول الكورساج مطابقاً للمقاس المطلوب حيث ازداد طوله بها يلائمم شكل الجسم. 
r- تنفيذ النماذج التى تم تسطيحها:

قامت الباحثة بتنفيذ النماذج التى تم تسطيحها على قماث الدمور وذلك بأريعـة مقاسـات

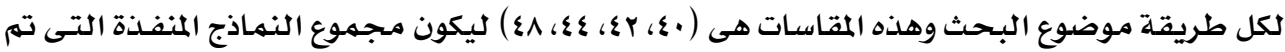

تسطيحها ثهان نهاذج.

وقد أخذت كل قطعة منفذه رقماً للدلالة على مقاسها ورمزرا للدلالة على الطريقـة المتبعـة

مِّْ تسطيح النموذج وكان ذلك كالتالى:-

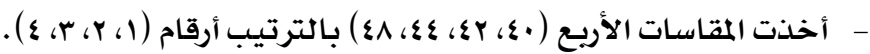

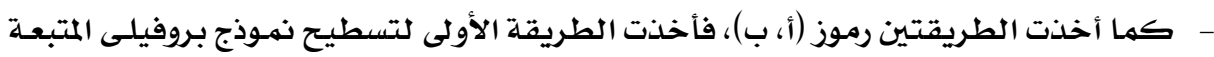

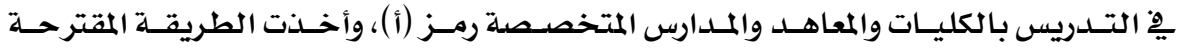

لتسطيح نموذج بروفيلى رمز (ب) .

- بعد ذلك تم تصوير كل مانيكان من ثلاث جهات (أمام - جنب - خلف) ـ ملحق (م). 


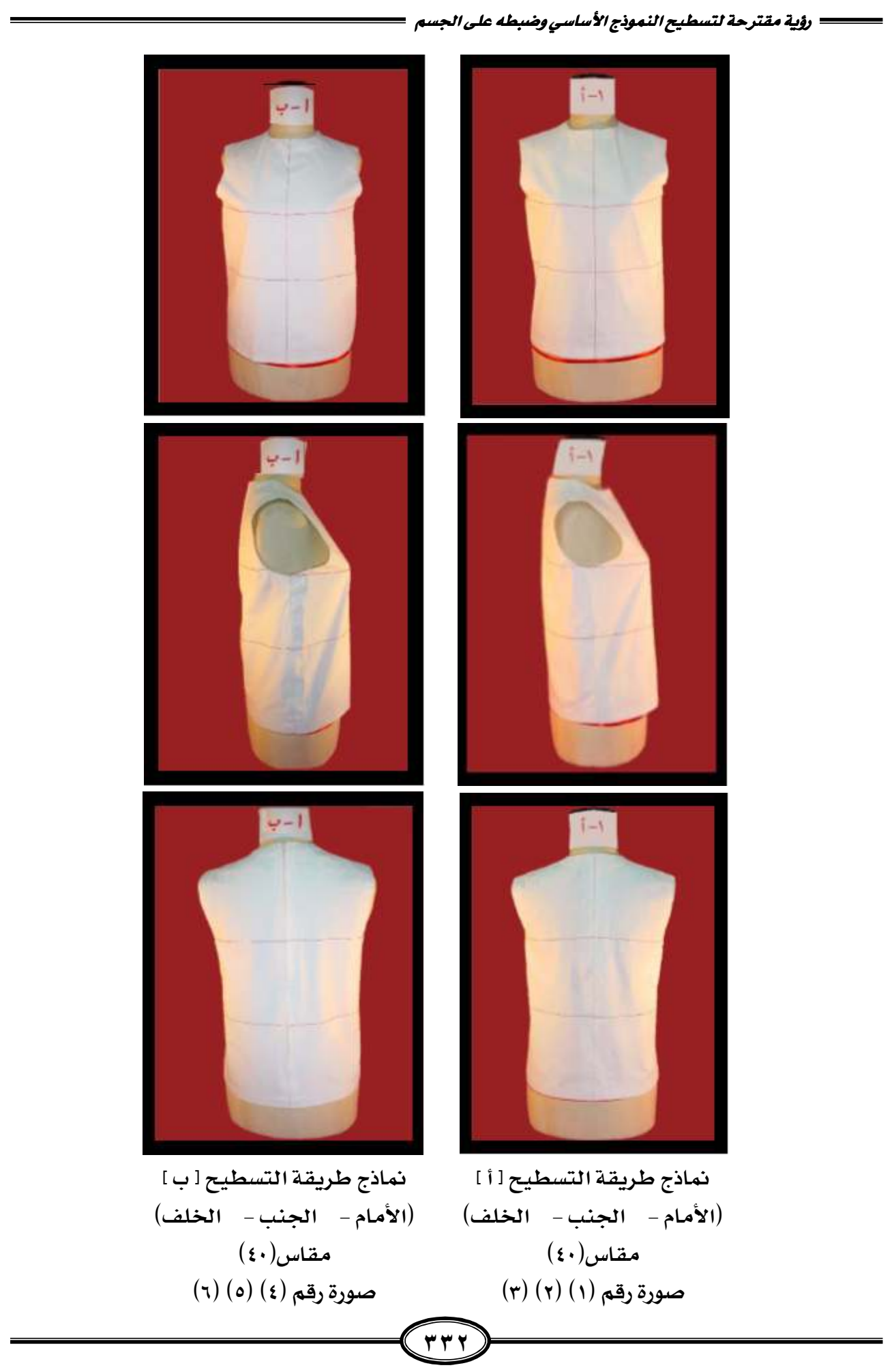




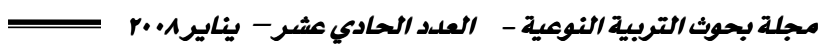
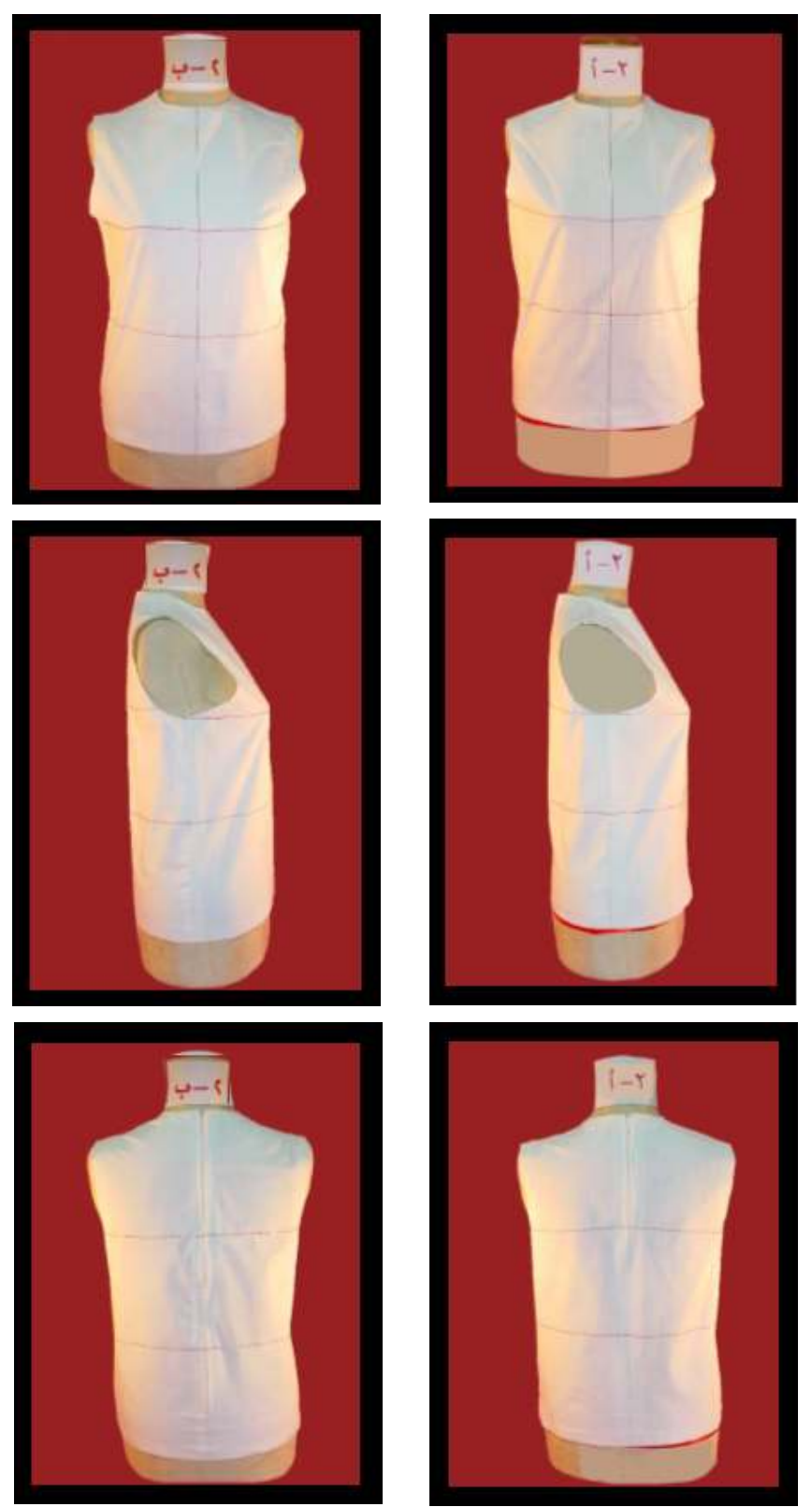

نهاذج طريقة التسطيح [ ب ]

نهاذج طريقة التسطيح [ أ ] الحمان

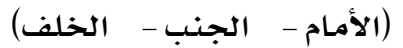

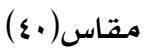

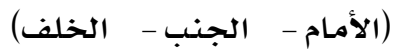

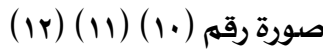
مقاس(r)

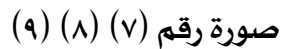




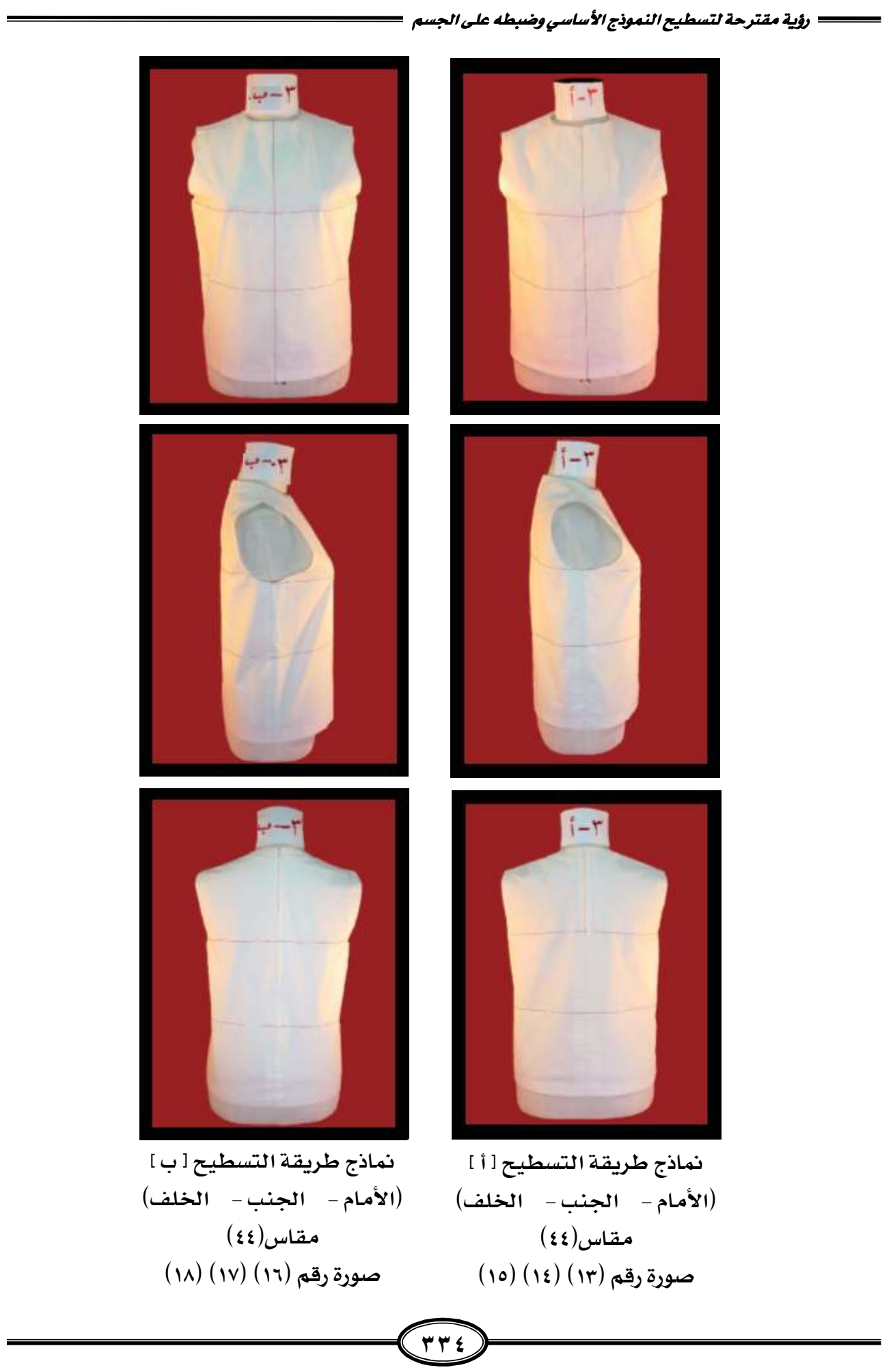




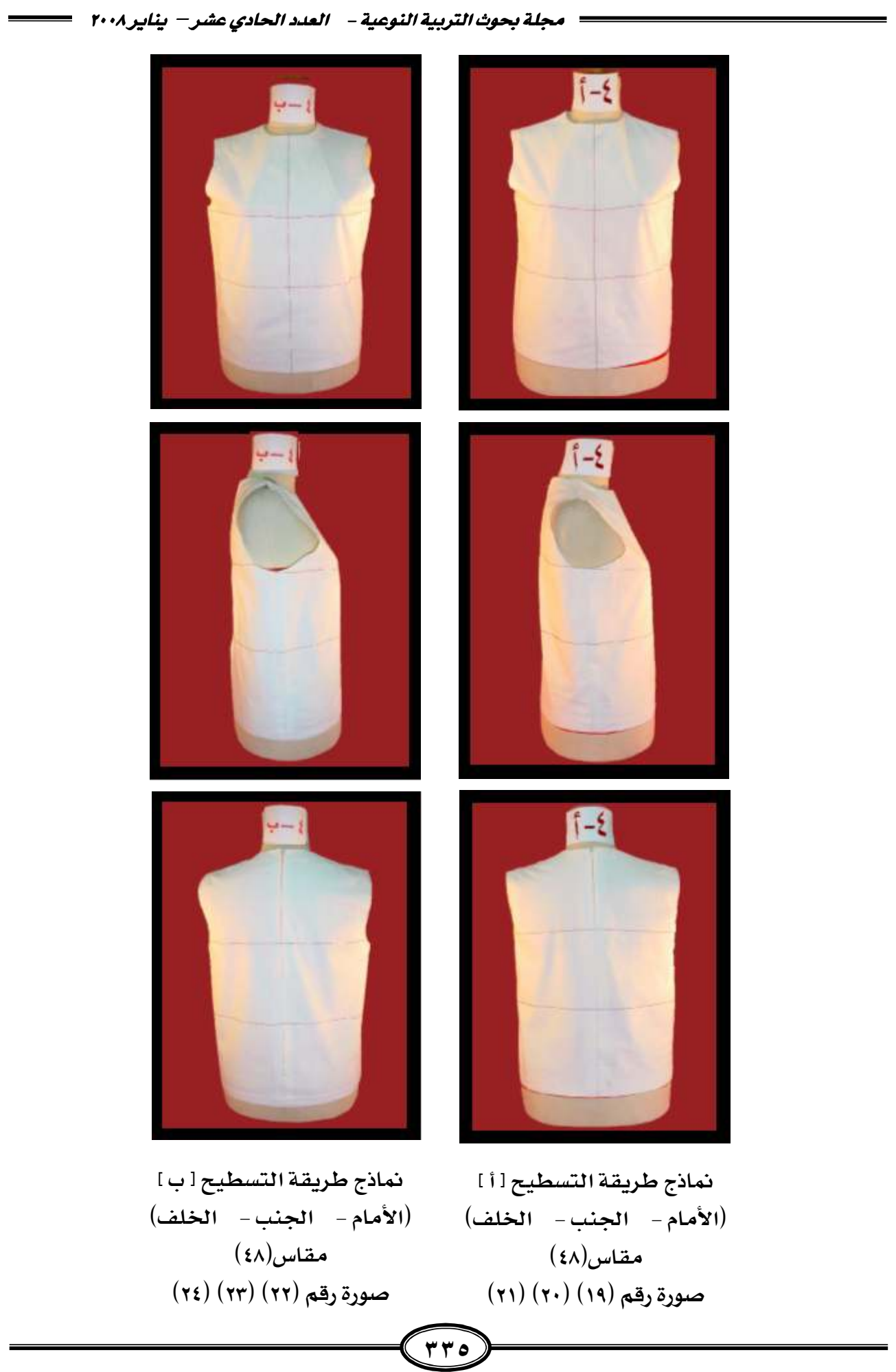




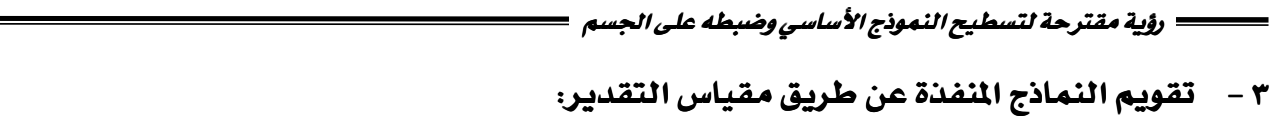

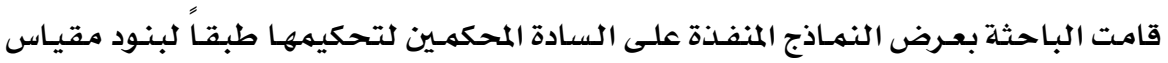

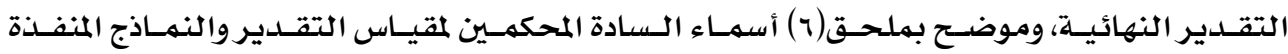
موضوع البحث . وقد قامت الباحثة بتفريغ البيانات ومعالجتها إحصائياً وجاءت النتائج كما يلى .

\section{نتائج البحث وتفسيرها:}

$$
\text { ـ الثرض الأول: ينص الفرض الأول على أنه: }
$$

- توجد فروق دالة إحصائياً بين طريقتى تسطيح النموذج الأساسي [الطريقة(i) المعتادة هوالطريقة (ب) المقترحة]،من حيث عناصر الضبط المختلفة للمقاسات( •ع) لصالح الطريقة (ب). وللتحقـق مـن هـــا الفـرض وللتعـرف على هـــه الفـروق وأى الطـريقتين أفضل تم معـالجــة

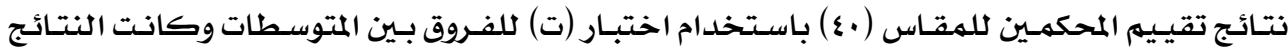
كما يوضحها الجدول التالى:-

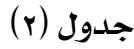

قيمة (ت) لدلالة الفروق بين المتوسطات لطريقتي تسطيح النموذج الأسـاسي للمقاس ( •ع) $r \mid=ن$

\begin{tabular}{|c|c|c|c|c|c|}
\hline الاتجـاه & الدلالة & قيمة (ت ) & $\varepsilon$ & م & الطرق \\
\hline لصاخح & $\nLeftarrow *$ & 0,9 & $\begin{array}{l}\varepsilon, Y \\
0,9\end{array}$ & $\begin{array}{l}111, r \\
111,1\end{array}$ & طريقة (ب) (أ) معتادة مقترحة \\
\hline
\end{tabular}

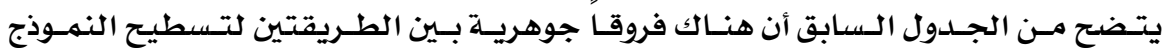

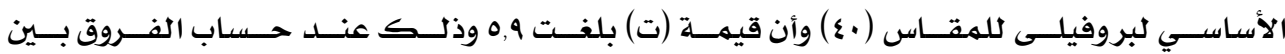

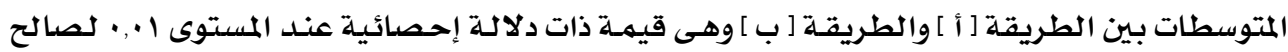
الطريقة [ب ].

ويتضح مما سبق أن الطريقة [ب] وهى الطريقة المقترحسة الأفضل يِّ الضبط عند مقارنتها

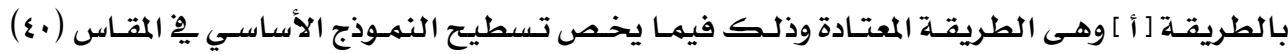
وبذلك يتحقق صحة الفرض الأول. ـ الثرض الثاذى: ينص الفرض الثانى على أنه: - توجد فروق دالة إحصائياً بين طريقتى تسطيح النموذج الأساسي [الطريقة(أ) المعتادة عوالطريقة

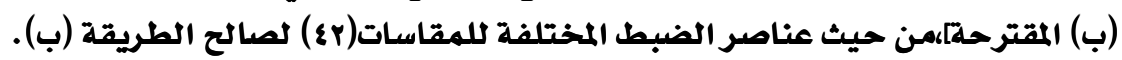


وللتحقـق مـن هــذا الفـرض وللتعـرف على هـذه الفـروق وأى الطـريقتتين أفضل تم معـالجــة

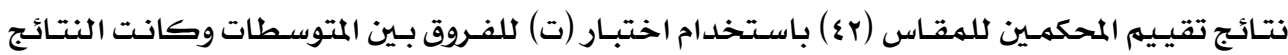

كما يوضحها الجدول التالى:-

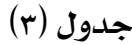

قيمة (ت) لدلالة الفروق بين المتوسطات لطريقتي تسطيح النهوذج الأساسي للمقاس (rع)

ن

\begin{tabular}{|c|c|c|c|c|c|}
\hline الاتجـاه & المعنوية & ت & $\varepsilon$ & r & الطرق \\
\hline [بالح & $* *$ & Y,, $\mathcal{E}-$ & $\begin{array}{l}0,7 \\
V, r\end{array}$ & $\begin{array}{l}111,7 \\
110,0\end{array}$ & طريقة (أ) معتادة \\
\hline
\end{tabular}

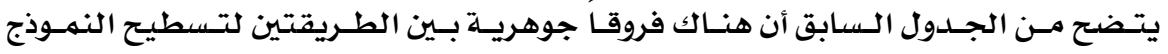

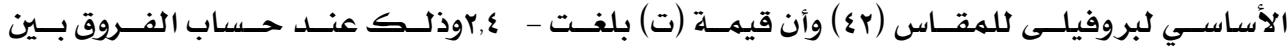

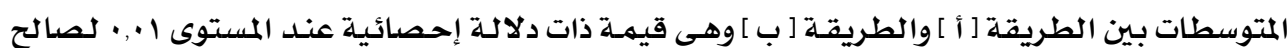
الطريقة [ب ].

ويتضح مما سبق أن الطريقة [ب] وهى الطريقـة المقترحسة الأفضل يِّ الضبط عند مقارنتها

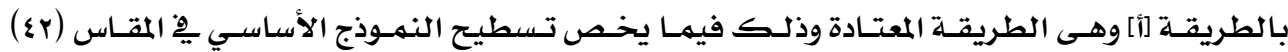

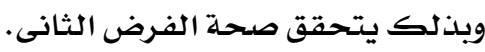
ـ الثرض الثالث: ينص الفرض الرابع على أنه:

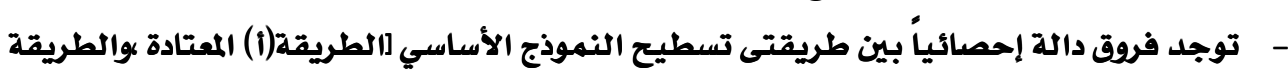

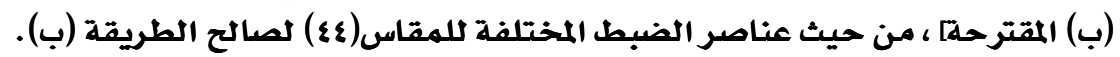
وللتحقـق مـن هــذا الفـرض وللتعـرف على هـذه الفـروق وأى الطـريقتين أفضل تم معـالجــة

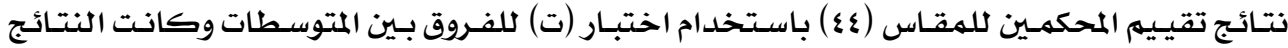
كما يوضحها الجدول التالى:جدول (ع)

قيمة (ت) لدلالة الفروق بين المتوسطات لطريقتي تسطيح النموذج الأسـاسي للمقاس(ع (ع) YI $=\dot{ }$

\begin{tabular}{|c|c|c|c|c|c|}
\hline الاتجاه & المعنويـة & ت & $\varepsilon$ & $\hat{r}$ & الطرق \\
\hline- & غير معنوية & $\cdot, 1 \varepsilon-$ & $V, q 9, r$ & $\begin{array}{l}1 \cdot 9,7 \\
1.9,9\end{array}$ & طريقة (ب) مقتر (أ) معتادة \\
\hline
\end{tabular}




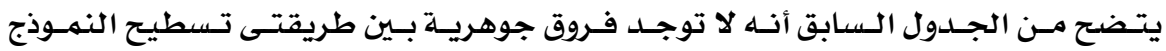

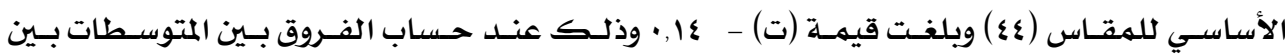

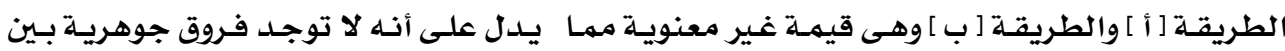

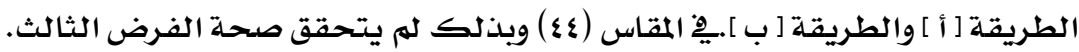

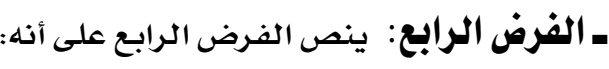

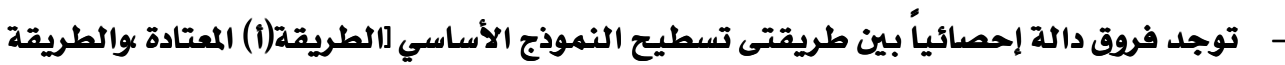

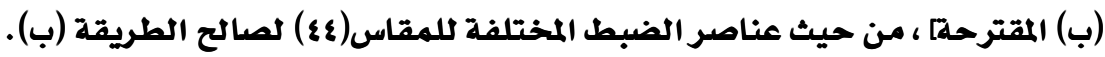

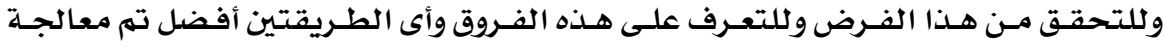

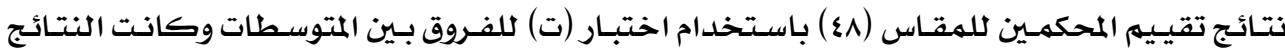
كما يوضحها الجدول التالي:جدول (0) - (0)

قيمة (ت) لدلالة الفروق بين المتوسطات لطريقتي تسطيح النموذج الأساسي للمقاس(ه؟) $r \mid=\dot{0}$

\begin{tabular}{|c|c|c|c|c|c|}
\hline الاتجاه & المعنويـة & ت & $\varepsilon$ & r & الطرق \\
\hline- & غير معنوية & $\cdot, 9 \varepsilon-$ & $\begin{array}{l}\Lambda, \Lambda \\
0,1\end{array}$ & $\begin{array}{l}11 \varepsilon, 9 \\
117,7\end{array}$ & الطريقة (ب) مقترحة ( أ ) معتادة \\
\hline
\end{tabular}

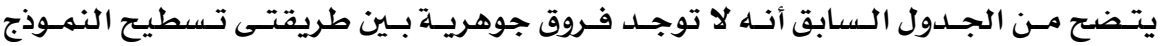

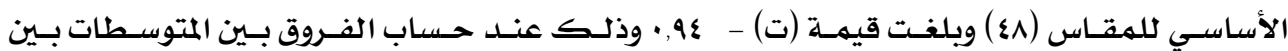

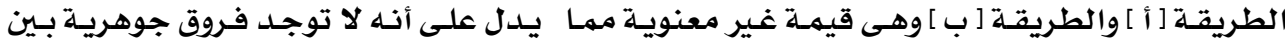

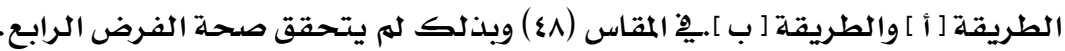

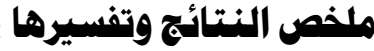

\section{يتضح من العرض السابق للنتائج الإحصائية مايلى:-}

وجدت فروق دالة إحصائياً بين طريقتى تسطيح النموذج الأساسي [الطريقة ( ا )، والطريقة

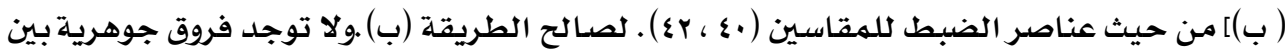
الطريقتين من حيث عناصر الضبط للهقاسين ( ع ، ، ع) . ويرجع هذا مـن وجهة نظر الباحثة إلى أن الطريقة ( ب ) تعالج كلاً من الأمام والخلف بهـا

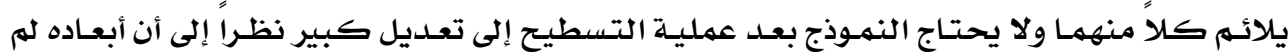

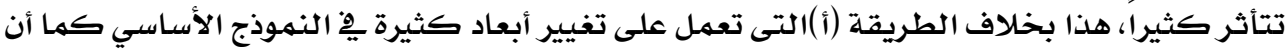

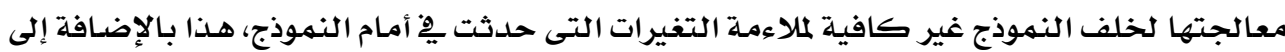

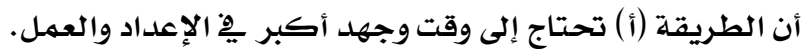


هِ ضوء نتائج البحث الحالى يمكن اقتراح التوصيات الآتية:-

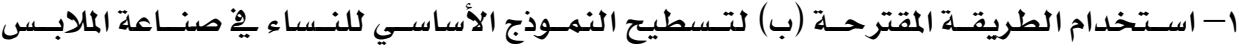
الجاهزة.

ب- استخدام الطريقة المقترحة (ب) لتسطيح النهـوذج الأساسي للنساء ِِِ قطـع مـلابس السيدات

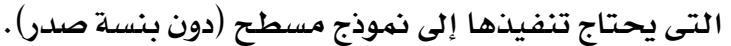

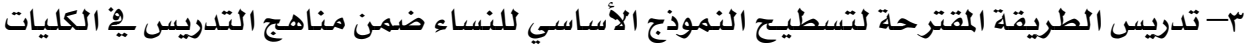
والمعاهد والمدارس المتخحصدة.

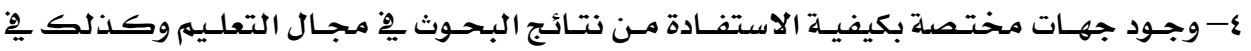
مجال الصناعة.

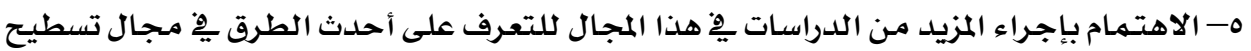
النموذج الأساسي للنساء التى تعطى أفضل ضبط لـنس للملابس. 


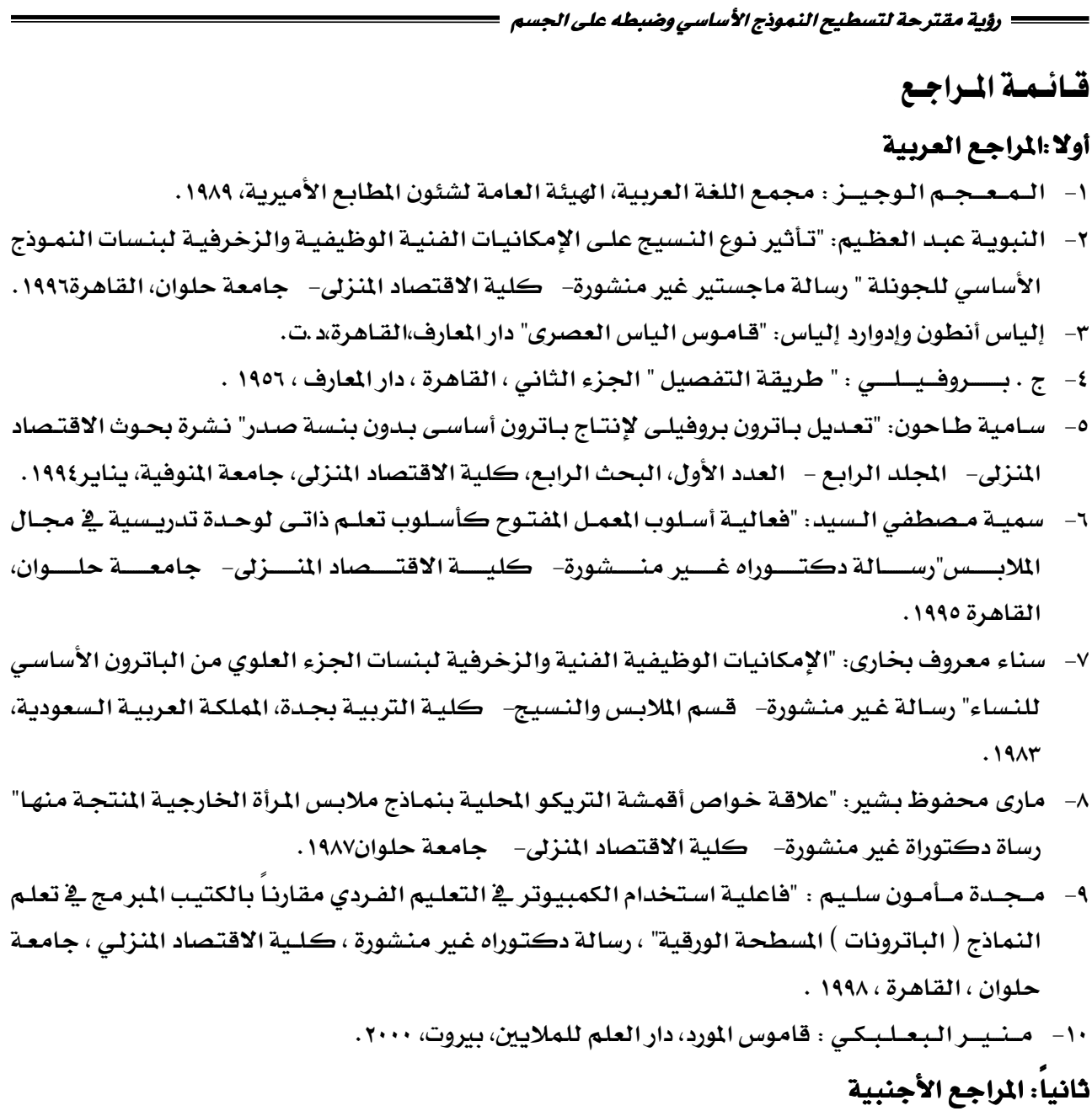

11- Aldrich, Winifred: "Fabric Form And Flat Pattern Cutting" Black Well Science Ltd London, 1996. $12-$ Ltd. , 1996 . : "Metric Pattern Cutting", Third Edition, Blackwell Science

13- Armstrong, Helen Joseph : "Pattern making For Fashion Design", Third Edition, Prentice - Hall , Inc., 2000.

14- Bane, Allyne: "Creative Clothing Construction" Third edition U.S.A., Macmillan Publishing Co., Inc., 1974.

15- $\quad$ : "Flat Pattern Designing" MC Graw. Hill Inc, New York, 1972.

16- Bray, Natalie : "Dress Pattern Designing "Fifth Edition, London, Granada Publishing, 1987.

17- Doyle, Tracy: "Sterling Publishing Co., Inc., New York, 1997. 
18- Hollen, Norma R. \& Kundel, Carolen G: "Pattern Making By Flat Pattern Methods" siventh Edition, Macmillan Publishing Co., U.S.A., 1993.

19- Margolis, Adele.P.: "Design Your Own Dress Patterns", Doubleday\& Company. Inc. New York, 1971.

20-__ : "Pattern Cutting For Women's Outerwear", Blackwell Science Ltd, First puplished, 1994.

21- Nora M. Macdonald: "Principles Of Flat Pattern Design Print In The U.S.A., Second edition Macmillan Ltd., New York, 1997.

22- Norma, Hollen: "Flat Pattern Methods", Burgess publishing company' Second edition' U.S.A., 1965

23- Reader's, digest: "Complete Guide To Sewing",the reader's digest association. Inc., New York, 1992.

24- Thomas, Anna Jacob : "The Art Of Sewing", fifth Reprint, Ubs Publisher' Distributors Ltd. , 1998. 